ENZO BERTAZINI

\title{
ANÁLISE DE FUNÇÕES DE UM CONVERSOR DE PROTOCOLOS DE COMUNICAÇÃO PARA AUTOMAÇÃO ELÉTRICA, BASEADO NA UTILIZAÇÃO DA LINGUAGEM DE MODELAGEM UNIFICADA
}

Dissertação apresentada à Escola Politécnica da Universidade de São Paulo para obtenção do Título de Mestre em Engenharia

São Paulo 
ENZO BERTAZINI

\section{ANÁLISE DE FUNÇÕES DE UM CONVERSOR DE PROTOCOLOS DE COMUNICAÇÃO PARA AUTOMAÇÃO ELÉTRICA, BASEADO NA UTILIZAÇÃO DA LINGUAGEM DE MODELAGEM UNIFICADA}

Dissertação apresentada à Escola Politécnica da Universidade de São Paulo para obtenção do Título de Mestre em Engenharia

Área de Concentração:

Sistemas de Potência

Orientador:

Prof. Dr. José Antonio Jardini

São Paulo 
Este exemplar foi revisado e alterado em relação à versão original, sob responsabilidade única do autor e com a anuência de seu orientador.

São Paulo, 05 de junho de 2006.

Assinatura do autor

Assinatura do orientador

\section{FICHA CATALOGRÁFICA}

Bertazini, Enzo

Análise de funções de um conversor de protocolos de comunicação para automação elétrica, baseado na Utilização da linguagem de modelagem unificada / E. Bertazini. -- ed.rev. --

São Paulo, 2006.

$59 \mathrm{p}$.

Dissertação (Mestrado) - Escola Politécnica da Universidade de São Paulo, Departamento de Engenharia de Energia e Automação Elétricas.

1. Protocolos de comunicação 2.UML 3.Programação orientada a objetos I.Universidade de São Paulo. Escola Politécnica. Departamento de Engenharia de Energia e Automação Elétricas II.t. 
Aos meus pais Ezio e Marceline, que sempre lutaram para que seus filhos recebessem a inalienável herança da educação e da cultura. 


\section{AGRADECIMENTOS}

Ao meu orientador Prof. Dr. José Antonio Jardini pela paciência, compreensão e estímulo.

Ao Prof. Dr. Luiz Carlos Magrini pelas informações valiosas na área de protocolos de comunicação.

A todos que, direta ou indiretamente colaboraram na execução deste trabalho. 


\section{RESUMO}

A evolução das técnicas de desenvolvimento de sistemas de software tem trazido melhorias na qualidade dos projetos desenvolvidos e na redução do tempo para seu desenvolvimento. Os conversores de protocolos sempre foram desenvolvidos através de técnicas análise, projeto e programação estruturada. Este trabalho tem por objetivo estudar as características da análise, projeto e programação orientados a objetos e sua aplicabilidade ao desenvolvimento de um conversor de protocolos de comunicação para a área de automação elétrica. Serão objetos deste estudo dois protocolos de comunicação com diferentes características de implementação sendo estes o protocolo IEC 60870-5-101 e o protocolo Modbus. O desenvolvimento obedece à sintaxe e semântica dos diagramas da UML (Unified Modeling Language), utilizando a ferramenta Rational Rose. 


\begin{abstract}
The evolution of the development software techniques has brought improvements in the quality of the developed projects and in the reduction of the time for its development. The converters of protocols had been always developed through techniques analysis, project and structuralized programming. This work has for objective to study the characteristics of the object-oriented analysis, project and programming and its applicability to the development of a converter of protocols of communication for the area of electric automation. Two protocols of communication with different characteristics of implementation will be objects of this study being the protocol IEC the 60870-5-101 and Modbus protocol. The development obeys the syntax and semantics of the diagrams of UML (Unified Modeling Language), using the Rational Rose tool.
\end{abstract}




\section{LISTA DE TABELAS \\ LISTA DE FIGURAS}

1 - INTRODUÇÃO.

1.1 - Sistemas de Supervisão e Controle do Sistema de Potência ...............................1

1.2 - Sistemas de Automação de Subestações, de Usinas e da Distribuição................3

1.2.1 - Sistemas de Automação de Subestações......................................................

1.2.2 - O Sistema de Automação de Usinas..............................................................4

1.2.3 - O Sistema de Automação da Distribuição ......................................................5

1.3 - Conceituação e Objetivos.......................................................................6

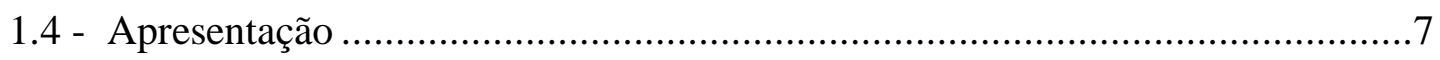

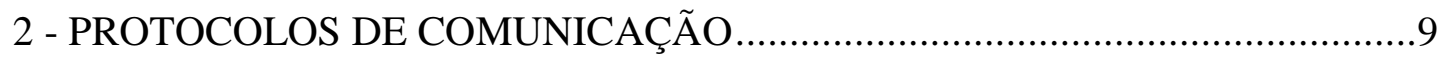

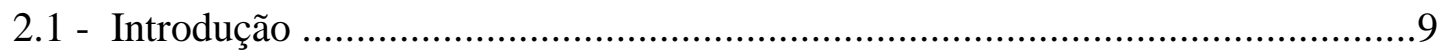

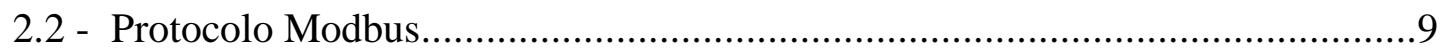

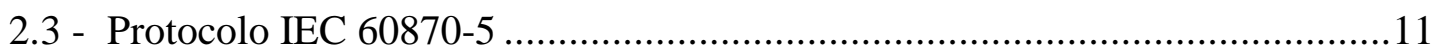

3 - MEtodologiA DE DESEnVOLVIMENTO - LinguAGEM DE

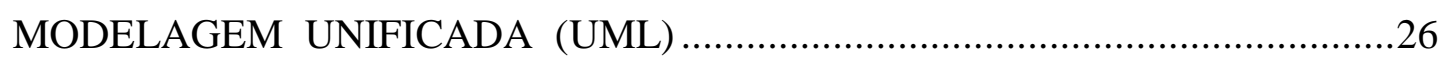

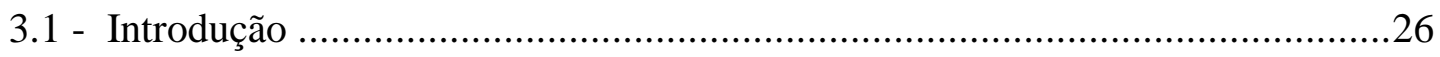

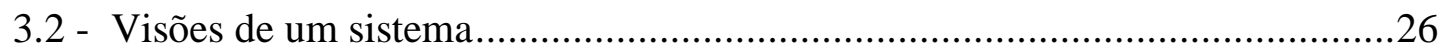

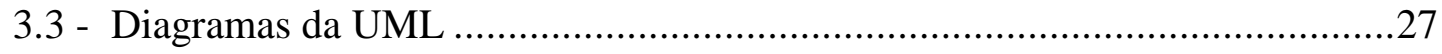

3.4 - A UML na Implementação do Conversor de Protocolos.................................28

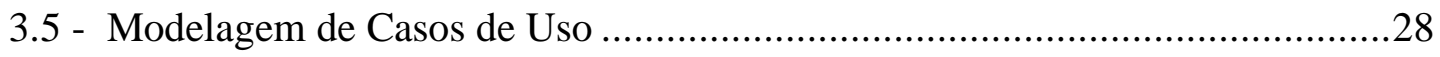

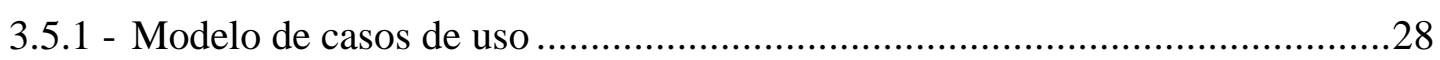

3.6 - Modelagem de Classes de Domínio ..........................................................29

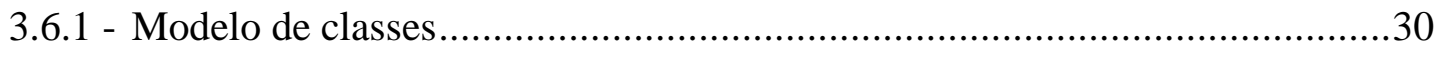

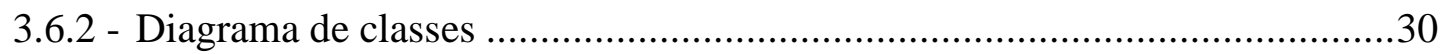

3.7 - Modelagem de Interações (Diagramas de Sequência) .....................................31

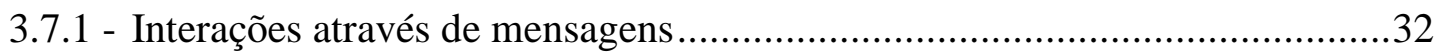

3.7.2 - - Sintaxe da UML e especificação de mensagens ......................................33 
3.8 - Modelagem de Estados

3.8.1 - Elementos de um Diagrama de transição de estados....................................35

4 - DESENVOLVIMENTO DAS FUNÇÕES DE CONVERSÃO DOS

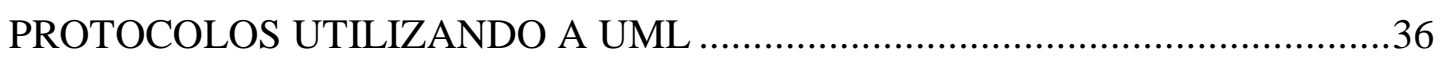

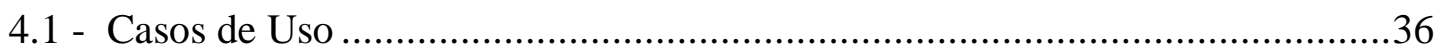

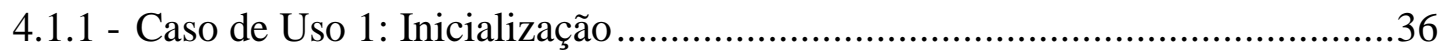

4.1.2 - Caso de Uso 2: Leitura de Entradas Digitais ................................................37

4.1.3 - Caso de Uso 3: Leitura de Entradas Analógicas ...........................................37

4.1.4 - Caso de Uso 4: Escrita de Valor Digital (Telecomando) ..............................38

4.1.5 - Diagrama de Casos de Uso do Conversor de Protocolos. ..............................39

4.2 - Modelos de Classes do Conversor de Protocolos............................................40

4.2.1 - Modelo de Classes de Domínio..................................................................40

4.2.2 - Modelo de Classes de Especificação ............................................................41

4.3 - Diagramas de Sequência dos Casos de Uso .................................................43

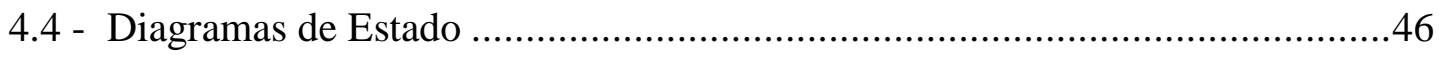

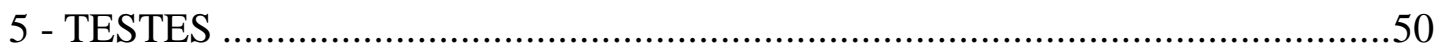

6 - CONCLUSÃO

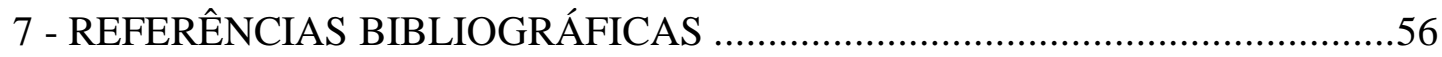

\section{LISTA DE TABELAS}

Tabela I- Sequência Request-Responde para Telecomando....................................25

Tabela II - Sequência Request-Responde para Telecomando .................................25

Tabela III - Sequência de Mensagens pata Inicialização ........................................52

Tabela IV - Sequência de Mensagens para Select ..............................................53

Tabela V - Legenda dos Campos das Mensagens IEC e Modbus.............................53

Tabela VI - Sequência de mensagens para Execute ..............................................54 


\section{LISTA DE FIGURAS}

Figura 1 - Hierarquia de um Sistema de Supervisão e Controle ...............................2

Figura 2 - Hierarquia de um Sistema de Automação de Subestação ...........................3

Figura 3 - Hierarquia de um Sistema de Automação de Usina ..................................4

Figura 4 - Atividades de um Sistema de Automação da Distribuição .........................5

Figura 5 - Diagrama de Blocos da Aplicação de um Conversor de Protocolos ...........7

Figura 6 - Estrutura de mensagem tipo Modbus ASCII. .........................................10

Figura 7 - Estrutura de mensagem tipo Modbus RTU............................................ 10

Figura 8 - Comparação entre os modelos ISO/OSI e EPA. ....................................12

Figura 9 - Formatação da camada de enlace. ...................................................... 14

Figura 10 - Tipos de frames do formato FT1 2 ............................................. 15

Figura 11 - Estrutura do campo Control Field ......................................................15

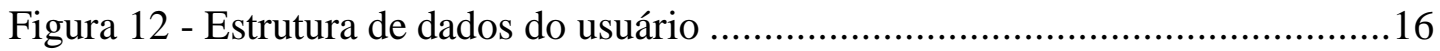

Figura 13 - Estrutura detalhada de uma ASDU ...................................................17

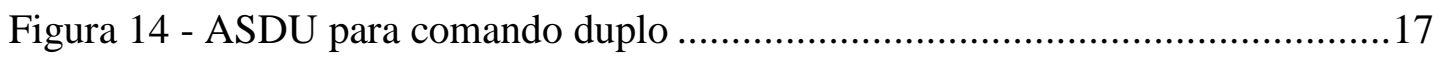

Figura 15 - Estrutura de mensagem de telecomando Modbus. ................................19

Figura 16 - Primitivas para request-respond ...................................................20

Figura 17 - Sequência Request-Responde para Incialização baseado em [7] ............21

Figura 18 - Sequência Request-Responde para Telecomando baseado em [7]..........23

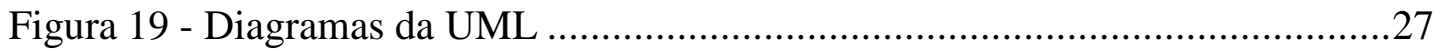

Figura 20 - Representação de um Caso de Uso .......................................................29

Figura 21 - Notações utilizadas para a representação de classes...............................31

Figura 22 - Construção de um Diagrama de Seqüência...........................................33

Figura 23 - Elementos de um diagrama de transição de estados...............................34

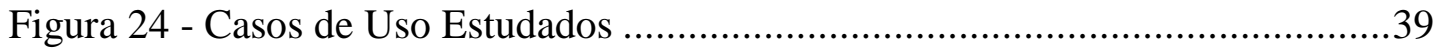

Figura 25 - Classes de domínio da implementação dos casos de uso 1 e 2 ...............40

Figura 26 - Classes de domínio da implementação dos casos de uso 3 e 4 ...............41

Figura 27 - Classes envolvidas na inicialização do centro de controle .....................41

Figura 28 - Classes envolvidas na solicitação de leitura de entradas digitais............42

Figura 29 - Classes envolvidas na solicitação de leitura de entradas analógicas .......42

Figura 30 - Classes envolvidas na solicitação de telecomando................................43

Figura 31 - Diagrama de seqüência para o caso de uso 1 (inicialização) ...................44 
Figura 32 - Diagrama de sequência para o caso de uso 4 (telecomando) ..................45

Figura 33 - Diagrama de estados da classe R_FRM_IEC.....................................46

Figura 34 - Diagrama de estados da classe E_FRM_IEC .....................................46

Figura 35 - Diagrama de estados da classe E_MSG_MOD ...................................47

Figura 36 - Diagrama de estados da classe R_MSG_MOD..................................47

Figura 37 - Diagrama de estados da classe CV_INIC .........................................47

Figura 38 - Diagrama de estados da classe CV_TC .............................................48

Figura 39 - Diagrama de estados da classe T_FRM_IEC na inicialização................48

Figura 40 - Diagrama de estados da classe T_FRM_IEC na seleção de ponto..........49

Figura 41 - Diagrama de estados da classe T_FRM_IEC na execução de comando .49

Figura 42 - Configuração de Hardware para testes da implementação. ....................50 


\section{1 - INTRODUÇÃO}

O sistema elétrico, desde a geração até o consumidor final, é um complexo conjunto de elementos interconectados e interdependentes.

Já faz algum tempo que os sistemas digitais vêm sendo utilizados na Automação Elétrica seja para a automação da geração, da transmissão ou distribuição de energia elétrica.

O termo Automação Elétrica tem sido usado para designar estes sistemas digitais que são utilizados para supervisão, comando, controle e proteção dos vários componentes do sistema elétrico [1].

Estes sistemas podem ser classificados, quanto ao processo a que estão relacionados em:

- Sistemas de supervisão do sistema de potência.

- Sistema de automação de subestações.

- Sistema de automação de usinas.

- Sistema de automação da distribuição.

Distinguem-se quanto às funções de comando, controle, supervisão e proteção que neles estão instaladas, portanto aos seus objetivos. Eles trocam informações entre si, de forma a executar suas funções, sem duplicação na coleta de dados e nas ações, estando ligados entre si através de uma rede de comunicação de dados que constitui a espinha dorsal destes sistemas [1].

\section{1 - Sistemas de Supervisão e Controle do Sistema de Potência}

Os sistemas de supervisão e controle do sistema de potência (SSC), também conhecidos por Sistema de gerenciamento da Energia (EMS - Energy Management System) fornece os mecanismos para a coordenação da operação e da manutenção do sistema elétrico. O SSC "enxerga" o sistema elétrico de uma forma global.

O SSC é composto por níveis hierárquicos, onde cada nível exerce determinadas funções e/ou ações. Na Figura 1 temos um exemplo de SSC.

No exemplo podemos verificar os seguintes níveis hierárquicos:

-UAC - unidade de aquisição e controle

-COR - centro de operação regional

-COS - centro de operação do sistema 


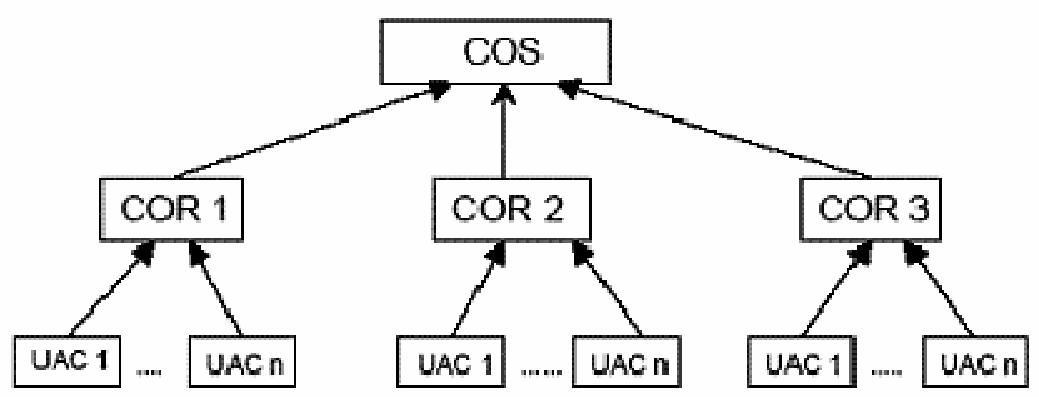

Figura 1 - Hierarquia de um Sistema de Supervisão e Controle

As UAC são microcomputadores/PLC/controladores, que são encarregados da interação com o processo. Elas são capazes de operar em ambientes hostis e com baixa taxa de falhas. Nelas ocorre a aquisição dos dados do campo e o comando de manobra dos equipamentos. As seguintes funções estão associadas a este nível hierárquico:

-Entrada de dados digitais;

-Entrada de dados analógicos;

-Saída digital;

-Saída analógica.

É comum encontrarmos algumas UAC's para cada subestação e usina. As UAC's se comunicam com o COR através de canal de telecomunicações.

No COR ocorrem a supervisão e o controle das subestações e usinas. Nele chegam todos os sinais que foram coletados pelas UAC's e é dele que partem os telecomandos para manobras de equipamentos. É no COR que reside a função SCADA (Supervisory Control and Data Aquisition) do sistema. O sistema SCADA é utilizado pelo operador do sistema elétrico para monitorar e controlar a rede. [1]

No COS é realizada a operação centralizada do sistema, bem como a coordenação da geração e da carga. Nele está localizado um sistema com as funções de "alto nível" que visam permitir a operação segura do sistema. Seguem alguns exemplos destas funções:

- Previsão de carga ligada; 
-Programação hidro-energética, previsão de cheias e vazões efluentes nos reservatórios;

-Fluxo de potência;

-Estimador de estado;

-Análise de contingência;

-Otimização da geração e transmissão;

-Controle automático de geração (CAG), ou o controle de carga e freqüência;

-Coordenação da manutenção, etc.

No Brasil existem vários SSC em operação e necessitam trocar informações entre si, visto que todos os sistemas de transmissão são interligados e, portanto interdependentes.

\section{2 - Sistemas de Automação de Subestações, de Usinas e da Distribuição.}

\subsection{1 - Sistemas de Automação de Subestações.}

O sistema utilizado para realizar estas funções pode variar em complexidade, mas será sempre composto por um sistema central, por um sistema de aquisição de dados e por unidades dedicadas (com algumas funcionalidades muito semelhantes as UAC) com finalidades específicas, como os relés digitais, por exemplo. Estes subsistemas são interligados normalmente por uma LAN, que pode ser, por exemplo, uma rede Ethernet [1]. Na Figura 2 temos um exemplo deste tipo de sistema.

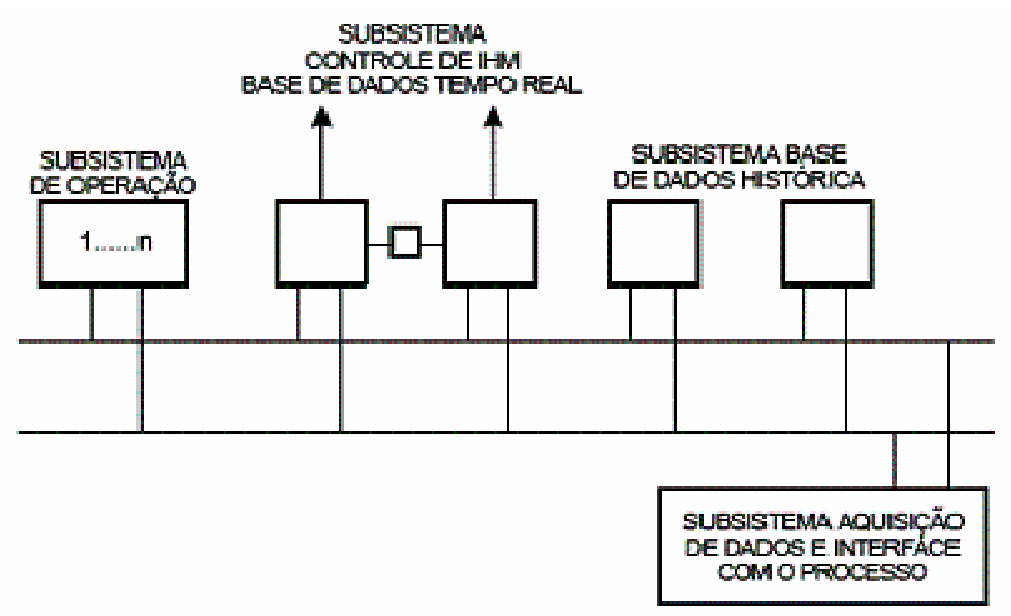

Figura 2 - Hierarquia de um Sistema de Automação de Subestação

Com relação aos aspectos de conectividade e possíveis trocas de equipamen- 
tos/tecnologias, para o sistema central tem-se adotado redes Ethernet. Para o protocolo de comunicação de dados deve ser adotado o modelo OSI sempre que possível, mas na prática o TCP/IP acabou dominando o mercado por ter se tornado um padrão "de fato".

Já no sistema de aquisição de dados o problema é maior. Há fabricantes especializados neste tipo de equipamento. Estes fabricantes fornecem redes próprias para interligar seus equipamentos e trabalham muitas vezes com protocolos proprietários.

\subsection{2 - O Sistema de Automação de Usinas}

Os sistemas utilizados para a automação de usinas são bastante parecidos com aqueles utilizados para a automação de subestações, diferenciando-se destes apenas em algumas funções, específicas da geração. A diferença no processo de geração da energia (usinas hidrelétricas, termoelétricas, etc.) também traz diferenças nas funções de automação.

A Figura 3 mostra uma configuração de um sistema de automação para uma usina hidrelétrica.

Existe uma semelhança do sistema de Automação de Usinas com os sistemas de automação de subestações. Fazem parte do subsistema de aquisição e controle equipamentos dedicados, como: relés de proteção, equipamentos reguladores de tensão, reguladores de velocidade dos geradores e controladores das comportas. Estes equipamentos se integram ao sistema via rede, como no caso dos relés de proteção digital ou via UAC, no caso dos reguladores e controladores.

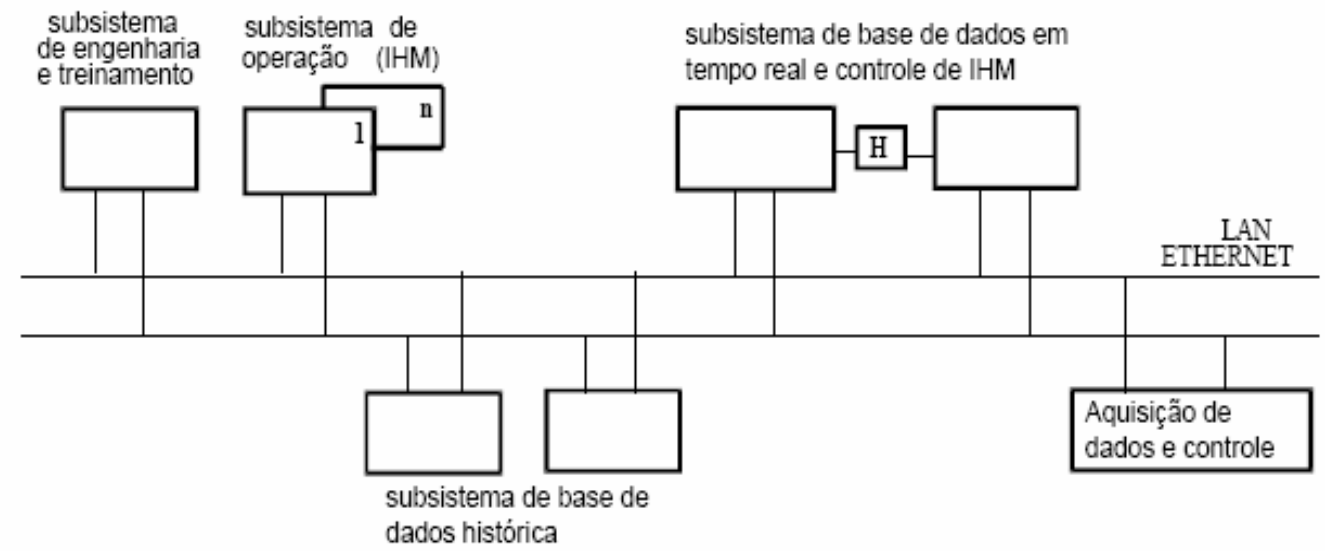

Figura 3 - Hierarquia de um Sistema de Automação de Usina 
Em grandes usinas, subsistemas independentes, que muitas vezes são operados isoladamente, se integram ao sistema geral de automação através da LAN.

\subsection{3 - O Sistema de Automação da Distribuição}

A distribuição de energia elétrica envolve atividades multidisciplinares que incluem engenharia, comercialização, administração, etc. A diretoria de distribuição de uma concessionária abrange vários departamentos que interagem e possuem sistemas computacionais específicos para exercer as suas atividades [1].

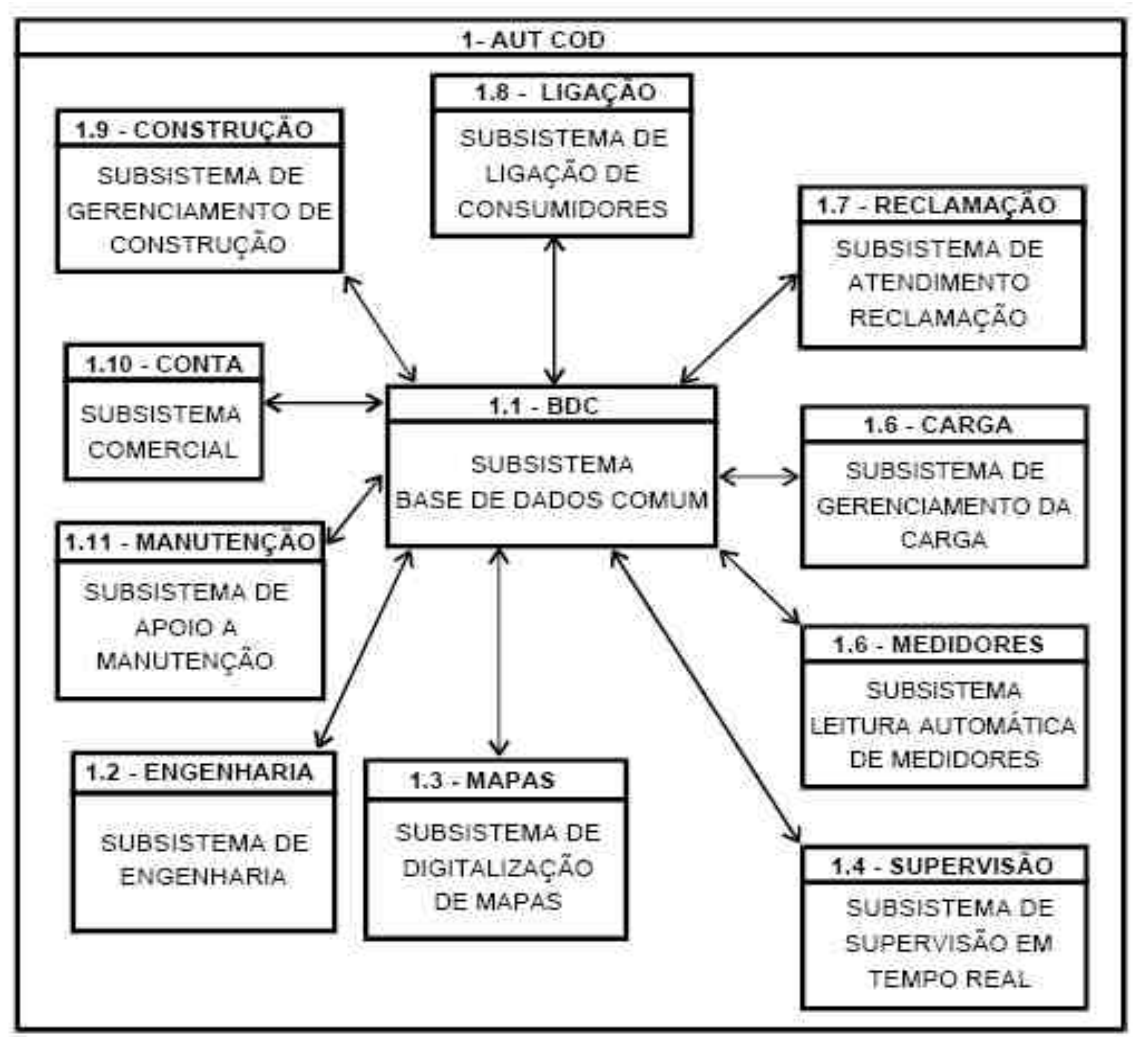

Figura 4 - Atividades de um Sistema de Automação da Distribuição

A automação da distribuição trata da integração destes sistemas digitais de forma que utilizem dados comuns e permitindo que eles mantenham sua independência e privacidade. Este sistema interage com outros sistemas da concessionária, como o Sistema de Supervisão e Controle da Geração/Transmissão (SSC ou EMS) e o Sistema Corporativo.

Este sistema, no que se refere à operação (COD), utiliza dados distribuídos na área de concessão e envia comandos a diferentes pontos. É de vital importância para 
este sistema, o meio de comunicação utilizado na transferência de dados entre o Sistema Computacional Central e as UAC e medidores.

O sistema de automação da distribuição é então composto por vários subsistemas que vão compartilhar uma base de dados comum para poder exercer as suas funções. A Figura 4 contém um esquema de como é constituído o sistema de automação da distribuição.

A integração destes sistemas heterogêneos em múltiplas plataformas é uma tarefa complexa que nem sempre conduz a resultados plenamente satisfatórios. A adoção de padrões internacionais facilita a interoperabilidade, mas por outro lado gera incertezas quanto ao futuro do padrão utilizado, no caso de existirem outros padrões com a mesma finalidade.

No caso dos protocolos voltados para a comunicação de dados no nível do campo com equipamentos específicos do setor elétrico os padrões têm aceitação regionalizada. O IEEE sugere a utilização dos protocolos DNP ou IEC 60870-5. Forças de mercado fizeram com que nos EUA o DNP 3.0 exerça um domínio quase absoluto, enquanto que na Europa o IEC 60870-5 é o mais utilizado.

Na comunicação de dados corporativa é utilizado o TCP/IP sobre Ethernet, que é suportado por praticamente todos os fabricantes.

\section{3 - Conceituação e Objetivos.}

Pela própria história do desenvolvimento do setor elétrico no Brasil, temos ainda hoje; mesmo após algumas modernizações localizadas que ocorreram na última década; um problema antigo e que devido a fatores econômicos deve se prolongar ainda por muito tempo. Este problema é referente à padronização dos protocolos de comunicação utilizados na comunicação entre esses componentes. Nos diferentes níveis de supervisão e controle da geração, transmissão e distribuição da energia elétrica no Brasil as diferentes concessionárias quando efetuam suas modernizações a fazem de forma parcial, com a utilização de novas UAC (Unidade de Aquisição Controle) muitas das quais utilizando protocolos de comunicação proprietários ou incompatíveis com os equipamentos antigos que não são substituídos. Outras vezes, o hardware e o software do COR e do COS são atualizados, mas não as UAC.

Esta dificuldade tem sido superada por iniciativa de órgãos internacionais que procuram padronizar protocolos de comunicação para equipamentos de automação 
elétrica. Especificamente, é interessante mencionar os protocolos IEC 60870-5 e o protocolo DNP 3.0, que definem as regras usadas na automação de sistemas elétricos para comunicação de equipamentos.

Em particular existem as aplicações específicas da norma IEC 60870-5, denominada IEC 60870-5/101 que detalha a comunicação de um Sistema Central com uma UAC, e a IEC 60870-5/103 que detalha a comunicação de um computador com relés digitais.

Para possibilitar a comunicação entre equipamentos com diferentes protocolos de comunicação, é necessária a utilização de um equipamento chamado conversor de protocolos. Os conversores de protocolos usualmente são implementados em hardware dedicado e software desenvolvido através de linguagens de programação estruturadas.

Este trabalho tem por objetivo estudar uma metodologia para o desenvolvimento de conversores de protocolos de comunicação empregando técnicas de análise, projeto e programação orientados a objetos. Estes conversores de protocolos de comunicação poderiam ser utilizados em qualquer um dos níveis de supervisão e controle para permitir a integração de novos equipamentos com os já existentes, visto que as iniciativas para adoção de um protocolo padrão só fazem sentido com a total substituição dos equipamentos existentes; em todos os níveis hierárquicos de automação. O diagrama de blocos da Figura 5 mostra a sua utilização.

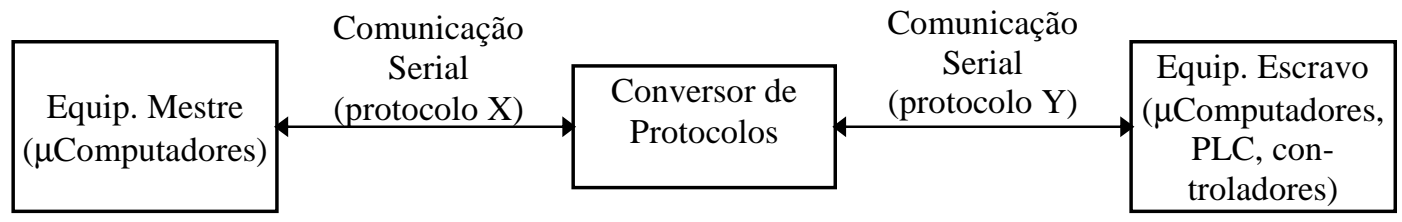

Figura 5 - Diagrama de Blocos da Aplicação de um Conversor de Protocolos

\section{4 - Apresentação}

Neste Capítulo 1, "INTRODUÇÃO" foi apresentada uma discussão sobre a constituição dos sistemas de automação usados no setor de energia elétrica, os objetivos deste trabalho e esta apresentação. 
No Capitulo 2 "PROTOCOLOS DE COMUNICAÇÂO" são apresentados os protocolos Modbus e IEC 60870-5 que serão tratados no decorrer deste trabalho.

No Capitulo 3, "METODOLOGIA DE DESENVOLVIMENTO - LINGUAGEM DE MODELAGEM UNIFICADA (UML)" linguagem visual para modelar programação orientada a objetos, usada neste trabalho.

No Capitulo 4, "DESENVOLVIMENTO DAS FUNÇÕES DE CONVERSÃO DOS PROTOCOLOS USANDO A UML" são apresentados os diagramas UML que especificam as funções desenvolvidas neste trabalho.

No Capitulo 5, "TESTES" é apresentada a plataforma de hardware utilizada para testes do software desenvolvido para confirmação do estudo realizado neste trabalho e as mensagens trocadas.

No Capitulo 6, “CONCLUSÃO” as observações relativas ao desenvolvimento deste trabalho. 


\section{2 -PROTOCOLOS DE COMUNICAÇÃO}

\section{1 - Introdução}

Para o foco no estudo de um conversor de protocolos, serão estudados dois protocolos de comunicação, que servirão de exemplo para a aplicação da metodologia a ser desenvolvida; o protocolo Modbus (padrão de fato) e o protocolo IEC 60870-5.

\section{2 - Protocolo Modbus}

É um protocolo utilizado para comunicação com controladores programáveis, atuadores, etc. Utiliza o método de acesso mestre-escravo, onde somente o mestre pode iniciar uma transação. As transações possíveis podem ser do tipo pergunta/resposta, onde apenas uma única estação é endereçada, ou do tipo broadcast, onde todas as estações escravas são endereçadas.

Cada transação compreende uma única mensagem de pergunta e somente uma única mensagem de resposta.

O Modbus admite até 247 equipamentos escravos, numa mesma rede física.

Ao receber uma mensagem o escravo após efetuar o teste de integridade de erros executa a ordem recebida, monta a estrutura de mensagem resposta e a envia ao mestre. Mensagens tipo broadcast, não necessitam de resposta [2].

A) Estrutura das Mensagens

O Modbus apresenta dois modos de transmissão. Os modos são denominados de ASCII (American Standard Code for Information Intercharge) e RTU (Remote Terminal Unit). Além da estrutura das mensagens estarem em modo caractere ou binário, os dois modos diferem também no método de detecção de erro, já que no ASCII é utilizado o LRC (Longitudinal Redundancy Check) enquanto que no modo binário é usado o CRC (Cyclical Redundancy Check). Quanto ao número de bits de dados para transmissão serial, no modo ASCII são usados 7 bits de dados por caractere, ao passo que no modo RTU são utilizados 8 bits de dados por caractere [2]. 
B) Estrutura das Mensagens Tipo ASCII

Todas as mensagens se iniciam pelo caractere dois pontos (“:”), que atua como demarcador de início de mensagem, enquanto que o Carriage Return (CR) e o Line Feed (LF) estabelecem o fim da mensagem. O caractere LF além de sinalizar o final da mensagem, indica ainda que a estação transmissora está apta para receber outra mensagem [2]. A estrutura desta mensagem é mostrada na Figura 6.

\begin{tabular}{|c|c|c|c|c|c|c|}
\hline $\begin{array}{c}\text { Início } \\
\text { Mensagem }\end{array}$ & Endereço & $\begin{array}{c}\text { Código } \\
\text { Função }\end{array}$ & Dados & $\begin{array}{c}\text { Detecção de } \\
\text { erro }\end{array}$ & $\begin{array}{c}\text { Fim da } \\
\text { mensagem }\end{array}$ & Pronta \\
\hline$:$ & 2 bytes & 2 bytes & n palavras de 2 bytes & 2 bytes (LRC) & CR (0x0D) & LF (0x0A) \\
\hline
\end{tabular}

Figura 6 - Estrutura de mensagem tipo Modbus ASCII.

\section{C) Estrutura das Mensagens Tipo RTU}

Neste tipo de frame não é utilizado caractere de sincronismo, pois decorrido o período de tempo equivalente a três e meio caracteres sem recepção de qualquer caractere, o equipamento encerra o frame corrente e assume que o próximo caráter a ser recebido será um caractere de endereço da mensagem seguinte[2]. A estrutura desta mensagem é mostrada na Figura 7.

\begin{tabular}{|c|c|c|c|c|c|}
\hline T1, T2, T3, T4 & Endereço & Função & Dados & Detecção de erros & T1, T2, T3, T4 \\
\hline & 8 bits & 8 bits & n caracteres de 8 bits & 16 bits (CRC) & \\
\hline
\end{tabular}

Figura 7 - Estrutura de mensagem tipo Modbus RTU.

D) Campo de Endereço

O endereço define univocamente o equipamento na rede. É utilizado tanto na mensagem de interrogação produzida pelo mestre, como na mensagem de resposta do escravo, a fim de identificá-lo.

E) Campo de Função

Define a operação a ser executada pelo escravo. Por sua vez o escravo devolve na sua mensagem o código da função realizada. Os códigos de função aceitos pelo Modbus estão relacionados abaixo:

01 - Read Coil Status 
02 - Read Input Status

03 - Read Holding Registers

04 - Read Input Registers

05 - Force Single Coil

06 - Preset Single Register

07 - Read Exception Status

08 - Diagnostics Subfunctions

11 - Fetch Comm Event Ctr

12 - Fetch Comm Event Log

15 - Force Multiple Coils

16 - Preset Multiples Regs

17 - Report Slave ID

20 - Read General Reference

21 - Write General Reference

22 - Mask Write 4x Registers

23 - Read/Write $4 x$ Registers

24 - Read FIFO Queue

Para a área de automação elétrica são mais frequentemente utilizadas as funções Modbus de códigos 02, 03. Além destes dois códigos são utilizados no desenvolvimento deste trabalho os códigos 05 e 08.

F) Campo de Dados

É utilizado pelo mestre para transferir parâmetros necessários à função solicitada ou ainda pelo escravo na sua resposta. Assim esse campo pode vir preenchido por valores, endereços de referência ou ainda limites.

\section{3 - Protocolo IEC 60870-5}

Este protocolo tem por objetivo atender os requisitos e condições para transmissão de dados em sistemas de telecontrole. Baseia-se nos conceitos do modelo ISO do Open System Interconnection (OSI), de três camadas denominadas EPA (Enhanced Performance Archtecture) [3]. A comparação entre as duas arquiteturas esta mostrada na Figura 8. 


\begin{tabular}{|c|c|c|}
\hline \multirow{2}{*}{$\begin{array}{l}\text { Camada } \\
7\end{array}$} & ISO/OSI & EPA \\
\hline & Aplicação & Aplicação \\
\hline 6 & Apresentação & \\
\hline 5 & Sessão & \\
\hline 4 & Transporte & \\
\hline 3 & Rede & \\
\hline 2 & Enlace & Enlace \\
\hline 1 & Física & Física \\
\hline
\end{tabular}

Figura 8 - Comparação entre os modelos ISO/OSI e EPA.

\section{A) Formatos de Frames}

A norma IEC 60870-5-1 buscando atingir o compromisso entre integridade de dados e transmissão de dados eficiente, e ao mesmo tempo não criar restrições aos dados do usuário, propõe três formatos distintos para as mensagens (FT 1.1 e FT 1.2, FT 2 e FT 3) [4], tentando dessa forma atender as mais diversas necessidades com relação a comprimento do caractere, comprimento dos frames, técnicas para detecção de erros, etc.

\section{B) Companion Standard 103}

Particulariza a norma IEC 60870-5 para comunicação com equipamentos de proteção. Nesse companion standard fica estabelecido que:

É utilizado como meio físico o EIA RS 485, suportando até 32 unidades de proteção por linha física, operando em 9600 ou 19200 bps.

Utiliza formato FT 1.2, sendo que o volume de dados do usuário fica limitado a 255 bytes.

Transmissão desbalanceada (mestre/escravo), sendo o relé sempre atuando como escravo.

O ASDU passa a apresentar somente um objeto de informação. O campo $D a$ ta Unit Identified passa a ocupar sempre 4 octetos.

São definidos 37 objetos de informação específicos para relés de proteção, bem como ASDUS específicos para monitoração e controle dos equipamentos. 


\section{C) Companion Standard 101}

Particulariza a norma IEC 60870-5 para comunicação com Unidades de Aquisição e Controle (UAC), tais como remotas e controladores programáveis [5]. Dentre elas podemos citar:

Aceita transmissão no modo balanceado e desbalanceado. No modo desbalanceado opera de forma assíncrona, admitindo taxa de transmissão até 9600 bps, enquanto que no modo balanceado faz uso do modo síncrono com taxas de até $56 \mathrm{kpbs}$.

Suporta configuração ponto a ponto, multiponto, estrela e anel.

Utiliza o formato FT1.2, com mensagens de comprimento fixo e variável.

Admite um ou dois bytes para endereçamento. Com um byte o endereço para broadcast é 255 , enquanto que para dois bytes o endereço de broadcast passa a ser 65535 ;

No modo polling usa o serviço request/respond;

Cada frame pode apresentar um único ASDU.

Foi suprimido o campo de comprimento do ASDU. Como o ASDU é único a extensão pode ser calculada a partir do comprimento do frame.

Especifica uma coleção de objetos para suporte às funções de monitoração e controle, incluindo transferência de arquivos, sincronização de relógio, sequiência de eventos, transferência de set-points [5].

D) Camada de Enlace

Proporciona três tipos de serviços básicos: transmissão sem/com confirmação e pergunta/resposta.

Estes serviços estabelecem uma seqüência de diálogos inseparáveis entre a estação que efetuou a interrogação e a estação a que responde, estando disponíveis em transmissões balanceadas e desbalanceadas.

As transmissões desbalanceadas são normalmente utilizadas em sistemas supervisórios, que se comporta como mestre interrogando ciclicamente todos os equipamentos conectados a ele (escravos). As estações remotas somente podem transmitir no instante em que são interrogadas. 
Já as transmissões balanceadas são restritas a configurações ponto a ponto, operando em modo duplex. Nesse tipo de conexão todas as estações têm o mesmo direito de transmissão, não existindo a figura do mestre.

A ASDU (Application Service Data Unit) é um bloco de dados que é transmitido de uma estação para outra.

De acordo com o modelo EPA alguma informação do tipo APCI (Application Protocol Control Information) é normalmente adicionada a ASDU para formar a APDU (Application Protocol Data Unit). No protocolo IEC 870-5-101 isto não é necessário tornando a APDU igual a ASDU [5].

A camada de enlace adiciona seu próprio LPCI (Link Protocol Control Information) ao APDU para formar o LPDU (Link Protocol Data Unit). Sua formação é mostrada na Figura 9:

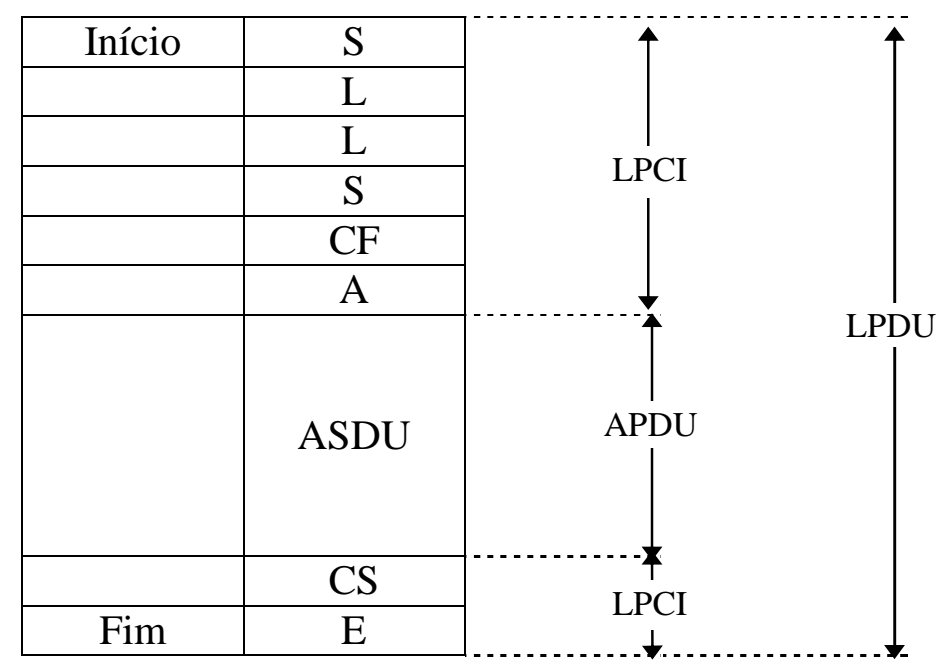

Figura 9 - Formatação da camada de enlace.

Os campos que formam o LPCI são:

$\mathrm{S}$ - Caractere de inicio do frame.

$\mathrm{L}$ - Comprimento do frame (0 a 255). Aparece duplicado.

CF - Control Field. Este campo contém informações que caracterizam a direção da mensagem, o tipo de serviço proporcionado e suporta funções que suprimem perda ou duplicação de mensagens.

A - Endereço (enlace).

CS - Check Sum.

E - Caractere de fim de frame. 
A Figura 10 mostra os três tipos de frames utilizados na camada de enlace da especificação IEC 60870-5-101 e que utiliza o formato de frame FT1.2 [4].

Frame de Tamanho

\begin{tabular}{|c|}
\hline Variável \\
\hline $\mathrm{S}=68 \mathrm{H}$ \\
\hline $\mathrm{L}$ \\
\hline $\mathrm{L}$ \\
\hline $\mathrm{S}=68 \mathrm{H}$ \\
\hline $\mathrm{CF}$ \\
\hline $\mathrm{A}$ \\
\hline $\mathrm{ASDU}$ \\
\hline $\mathrm{CS}$ \\
\hline $\mathrm{E}=16 \mathrm{H}$ \\
\hline
\end{tabular}

Frame de Tamanho

\begin{tabular}{|c|}
\multicolumn{1}{c|}{ Fixo } \\
\hline $\mathrm{S}=10 \mathrm{H}$ \\
\hline $\mathrm{CF}$ \\
\hline $\mathrm{A}$ \\
\hline $\mathrm{CS}$ \\
\hline $\mathrm{E}=16 \mathrm{H}$ \\
\hline
\end{tabular}

Caracter Simples

ACK

E5 H

Figura 10 - Tipos de frames do formato FT1.2

Para os frames de tamanho variável e de tamanho fixo o campo CF (Control Field) é detalhado a seguir. A Figura 11 mostra a estrutura dos bits que formam esse campo.

\begin{tabular}{|c|c|c|c|cc|c|}
\hline 8 & 7 & 6 & 5 & 4 & 1 & $\leftarrow$ bits \\
\hline \multirow{2}{*}{ RES } & \multirow{2}{*}{ PRM } & FCB & FCV & \multirow{2}{*}{ Função } & & utilizados no sentido mestre-escravo \\
& & ACD & DFC & & utilizados no senido escravo-mestre \\
\hline
\end{tabular}

Figura 11 - Estrutura do campo Control Field

RES - Reservado (utilizado em comunicações balanceadas)

FCB - Frame count bit: alterna entre 0 e 1, sendo utilizado na detecção de perdas e duplicação de informações. A cada nova mensagem o mestre alterna esse bit (para um mesmo escravo).

FCV - Frame count bit valid: habilita (=1) ou desabilita (=0) o FCB, nas mensagens do mestre para o escravo.

DFC - Existe apenas nas mensagens do escravo para o mestre, sendo utilizado para indicar que o escravo está com sua área de buffer esgotada, e qualquer mensagem adicional poderá causar um overflow.

ACD - Existe apenas no sentido escravo, mestre. Indica a disponibilidade de dados classe 1 (eventos ou mensagens de prioridade elevada) para ser transmitido ao mestre. 
PRM - Indica o sentido das mensagens:

$=0$ mensagem proveniente do escravo;

$=1$ mensagem proveniente do mestre.

Function Code - Ocupa os 4 bits menos significativos. Apresenta códigos para confirmação ou negação de mensagens, além de código para transmissão de dados. Os serviços disponibilizados pelos códigos de função possíveis são: send/reply (utilizados para mensagens globais e setpoints cíclicos), send/confirm (utilizados em mensagens de comandos e setpoints) e request/respond (utilizados em leituras cíclicas).

E) Camada de Aplicação

Define estrutura para os dados do usuário, denominada de ASDU (Application Service Data Unit) [6]. Conforme pode ser observado na Figura 12, cada ASDU é composta de uma estrutura Data Unit Identifier, seguida de várias estruturas do tipo Information Object. O ASDU é encerrado pela Common Time Tag.

Uma ASDU geral poderia ser assim representada:

Início

Fim

\begin{tabular}{|c|c|c|c|}
\hline $\begin{array}{c}\text { Data Unit } \\
\text { Identifier }\end{array}$ & $\begin{array}{c}\text { Information } \\
\text { Object 1 }\end{array}$ & - & $\begin{array}{c}\text { Information } \\
\text { Object } n\end{array}$ \\
\hline
\end{tabular}

Figura 12 - Estrutura de dados do usuário

F) Estrutura de uma ASDU

Uma estrutura do tipo "Data Unit Identifier" possui sempre a mesma estrutura para todas as ASDU. Os campos "Information Object" de uma ASDU terão sempre a mesma estrutura e tipo, que forem definidas no campo "Type Identification" [5]. A figura 13 mostra esta estrutura. 


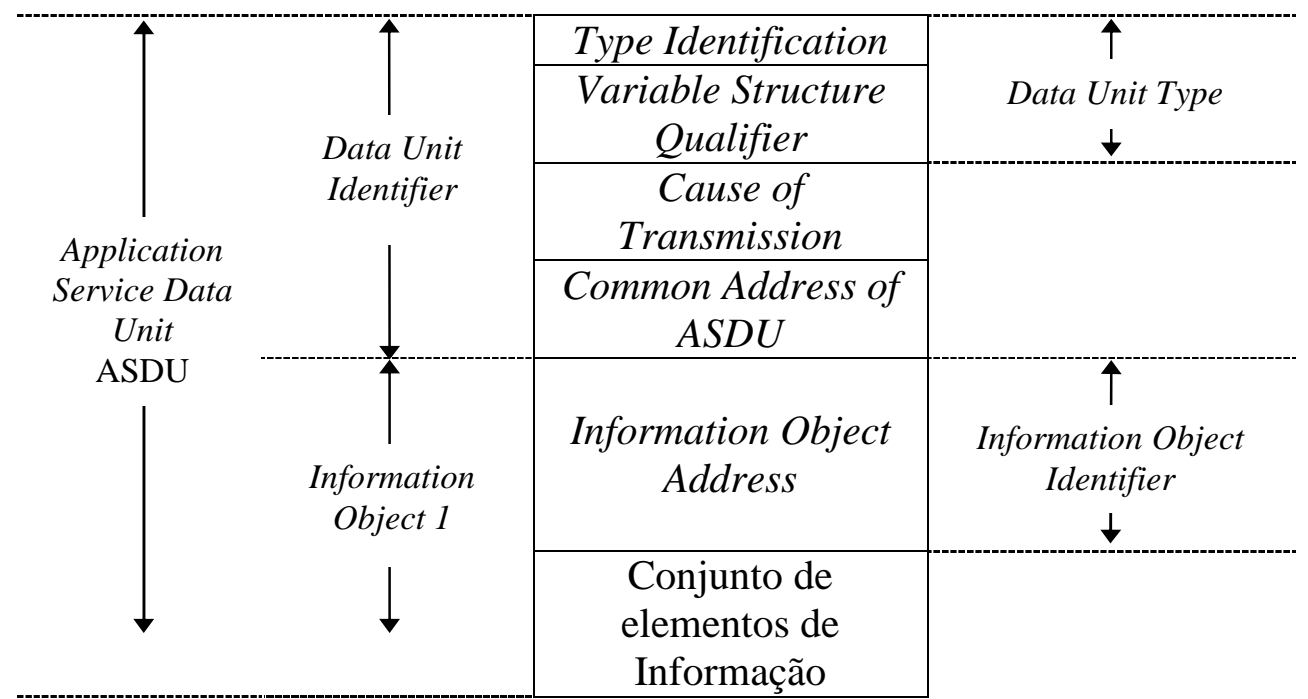

Figura 13 - Estrutura detalhada de uma ASDU

G) Exemplo da ASDU para função de telecomando (comando duplo - SBO)

A figura 14 mostra como é formada a ASDU para um comando duplo quando da utilização frames de tamanho variável.

Bits

\begin{tabular}{|c|c|c|c|c|c|c|c|c|c|}
\hline 8 & 7 & 6 & 5 & 4 & 3 & 2 & 1 & \multicolumn{2}{|l|}{ Estruturas } \\
\hline 0 & 0 & 1 & 0 & 1 & 1 & 1 & 0 & Type Identification $=46$ & \multirow{4}{*}{$\begin{array}{r}\text { DATA UNIT } \\
\text { IDENTIFIER }\end{array}$} \\
\hline 0 & 0 & 0 & 0 & 0 & 0 & 0 & 1 & Variable Structure Qualifier & \\
\hline \multicolumn{8}{|c|}{ Definido em G.1 } & Cause of Transmission & \\
\hline \multicolumn{8}{|c|}{ Definido em G.2 } & Common Address of ASDU & \\
\hline \multicolumn{8}{|c|}{ Definido em G.3 } & Information Object Address & \multirow{2}{*}{$\begin{array}{c}\text { OBFORMATION } \\
\text { OBJECT }\end{array}$} \\
\hline $\mathrm{S} / \mathrm{E}$ & \multicolumn{5}{|c|}{ QU } & \multicolumn{2}{|c|}{ DCS } & DCO: Definido em G.4 & \\
\hline
\end{tabular}

Figura 14 - ASDU para comando duplo

\section{G.1 - Cause of Transmission}

Na direção de controle (UAC):

$$
\begin{aligned}
& 6 \text { = ativação, } \\
& 8=\text { desativação. }
\end{aligned}
$$

Na direção de monitoração (sistema SCADA):

7 = confirmação de ativação, 
9 = corfimação de desativação,

10 = término de ativação.

\section{G.2 - Common Address of ASDU}

Endereço das estações (UACs):

0 = não utilizado,

1 a $65534=$ endereços validos para estações,

65535 = endereço global (para todas as estações).

\section{G.3 - Information Object Address}

$0=$ Endereço de objeto de informação irrelevante.

de 1 a 65535 = Endereços de objeto de informação válidos

\section{G.4 - DCO (duplo comando)}

DCS (estado do duplo comando):

0 e 3 = não permitido,

$1=\mathrm{OFF}$,

$2=\mathrm{ON}$.

QU (qualificação do comando):

$0=$ sem definição adicional,

1 = pulso de curta duração (depende do sistema),

2 = pulso de longa duração (depende do sistema),

3 = saída persistente,

4 a 8 = reservado para definições futuras do padrão,

9 a 5 = reservado para seleção de outras funções pré-definidas,

16 a 31 = reservados para uso especial (faixa particular).

S/E (select/execute)

$0=$ Execute,

$1=$ Select

Para os frames de tamanho fixo a função de comando solicitada está inserida dentro do campo Control Field, como especificado no sub-item D do item 2.3. 
H) Exemplo da função de telecomando Modbus(Force Single Coil - 05)

A figura 15 mostra como é formada a mensagem Modbus para solicitação de execução de um comando, não estando representada a palavra de 16 bits de controle de erro. No protocolo Modbus a execução do comando é direta, não existindo a seleção prévia do ponto a ser comandado.

\begin{tabular}{|c|c|c|c|c|c|}
\cline { 3 - 6 } \multicolumn{2}{c|}{} & \multicolumn{4}{c|}{ Dados } \\
\hline Endereço UAC & Função & \multicolumn{2}{|c|}{ Coil Address } & \multicolumn{2}{c|}{ Force Data } \\
\hline 8 bits & 8 bits & Hi & Lo & Hi & Lo \\
\hline Definido em H.1 & 05 & \multicolumn{2}{|c|}{ Definido em H.2 } & \multicolumn{2}{|c|}{ Definido em H.3 } \\
\hline
\end{tabular}

Figura 15 - Estrutura de mensagem de telecomando Modbus.

\section{H.1 - Endereço da UAC}

$0=$ endereço global (para todas as UAC)

1 a 247 = endereços válidos para cada UAC individualmente

\section{H.2 - Coil Address}

0 a 65535 = endereço válidos para pontos a serem comandados. O maior número permitido dentro da faixa possível de endereçamento depende exclusivamente do modelo de controlador Modbus utilizado como UAC.

\section{H.3 - Force Data}

$$
\begin{aligned}
& \mathrm{Hi}=255 \text { e Lo }=0-\text { solicitação para comando } O N . \\
& \mathrm{Hi}=0 \text { e Lo }=0-\text { solicitação para comando } O F F .
\end{aligned}
$$

I) Procedimentos de request-respond para modo desbalanceado.

Cada aplicação de monitoração e controle pode ter uma "função principal da aplicação" e uma "função secundária da aplicação". Uma "função principal” é a parte da aplicação responsável por solicitar a aplicação remota por meio da "função secundária" informações necessárias a execução da aplicação. Tarefas solicitadas são executadas por meio de serviços de comunicação sequenciais. Os serviços de comunicação sequenciais são descritos por sequências de primitivas [7]. 
As primitivas utilizadas nos procedimentos de request-repond são:

Serviço.request ( .req): A aplicação principal inicia a solicitação através desta primitiva para a aplicação secundária por meio dos serviços de comunicação.

Serviço.indicação ( .ind): os seviços de comunicação utilizam esta primitiva para entregar a aplicação secundária a indicação da solicitação.

Serviço.response ( .res): A aplicação secundária usa esta primitiva para responder a solicitação proveniente dos serviços de comunicação.

Serviço.confirm ( .con): Os serviços de comunicação utilizam esta primitiva para entregar para a aplicação principal a resposta da aplicação secundária.

A figura 16 mostra as primitivas utilizadas em serviços com e sem confirmação.

Serviço sem confirmação

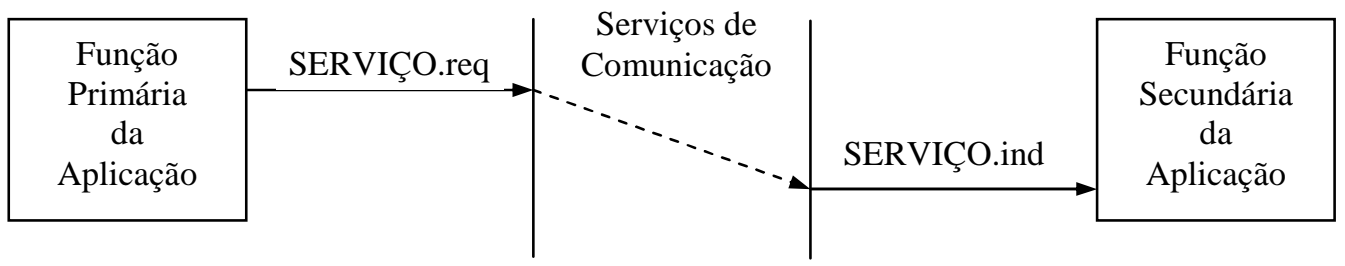

Serviço com confirmação

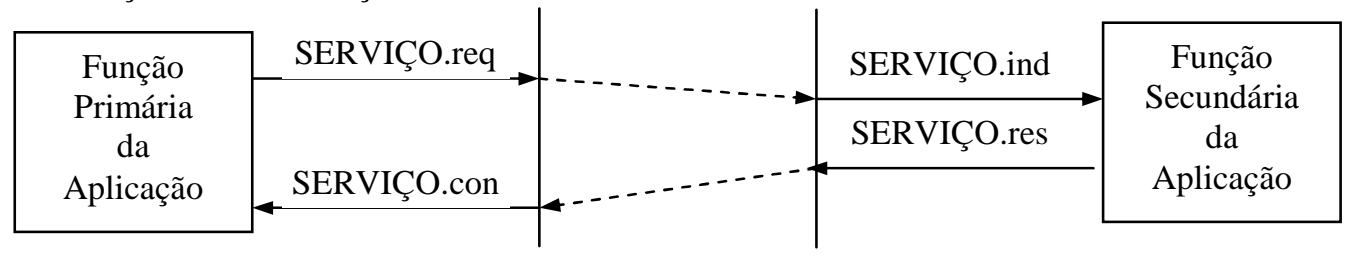

Figura 16 - Primitivas para request-respond

Neste trabalho serão implementadas para confirmação do estudo desenvolvido as funções de inicialização e de telecomando que têm o detalhamento das sequências request-respond realizadas a seguir.

J) Sequência de Request-Respond para Inicialização.

$\mathrm{Na}$ inicialização da estação de controle, solicita-se o status do link de comunicação e o posterior reset do mesmo. Esta sequência de operações pode ser realizada somente entre a estação de controle (SCADA) e o conversor de protocolos, pois o protocolo Modbus não possui este tipo de procedimento. A Figura 17 mostra a sequência de procedimentos para a inicialização. 


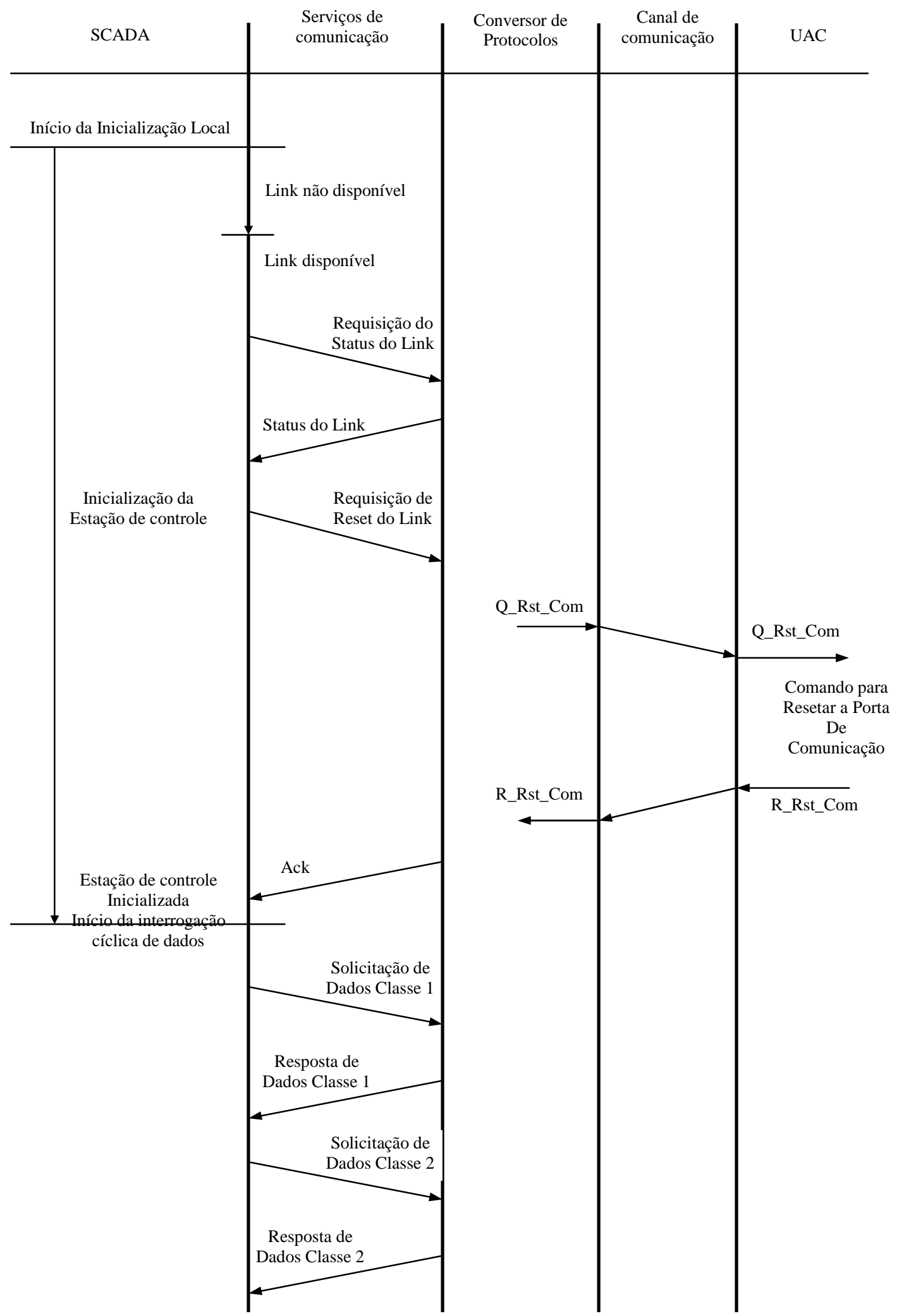

Figura 17 - Sequência Request-Responde para Incialização baseado em [7] 
Com o objetivo de promover uma melhor iteração entre estação de controle e UAC, foi incluída nesta sequência de procedimentos o envio para a UAC de uma função que solicita o reset da porta de comunicação serial da mesma. O detalhamento dos procedimentos será realizado no capítulo 4.

Após a inicialização da estação de controle, entra em um processo de solicitação cíclica de dados, solicitando dados de classe 1 e classe 2 .

O conjunto de protocolos da norma IEC 60870-5, especifica duas classes de dados, os dados classe 1 e classe 2. Os dados de classe 1 (espontâneos) são relativos a eventos registrados pela UAC. Os dados de classe 2 são referentes a informações que devem ser constantemente atualizadas na estação de controle.

Em um sistema SCADA a aquisição de dados é realizada de forma cíclica (polling) operando em modo desbalanceado com o objetivo de atualizar a estação de controle com os valores de variáveis de processo existentes nas UAC. Neste caso as UAC só transmitem informações quando estas são solicitadas.

O companion standard IEC 870-5-101 especifica os serviços de link Request user data class 2 para ser usado na solicitação cíclica de dados existentes nas UAC e Request user data class 1 para a solicitação de dados espontâneos.

Em caso de só ser utilizado o serviço Request user data class 2 na realização da leitura cíclica, uma reposta pode conter no campo Control Field a sinalização de que existem dados classe 1 para serem lidos. Neste momento um serviço Request $u$ ser data class 1 pode ser solicitado para a leitura dos mesmos.

O protocolo Modbus não contempla dados classificados em classes tendo em suas funções apenas tipos de dados que podem ser lidos por leitura cíclica, sendo compatíveis com a definição de dados classe 2 do protocolo IEC 60870-5.

Para a compatibilização destes tipos de dados entre o protocolo IEC 60870-5101 e o protocolo Modbus, o conversor de protocolos tem a função de responder a uma solicitação de dados classe 1 com a indicação Requested data not available.

K) Sequência de Request-Respond para Telecomando.

A Figura 18 mostra a sequência de procedimentos para telecomando. Para a execução de um telecomando no protocolo IEC 60870-5-101 é necessária a solicitação de seleção do ponto a ser comandado, a resposta de confirmação da seleção do 


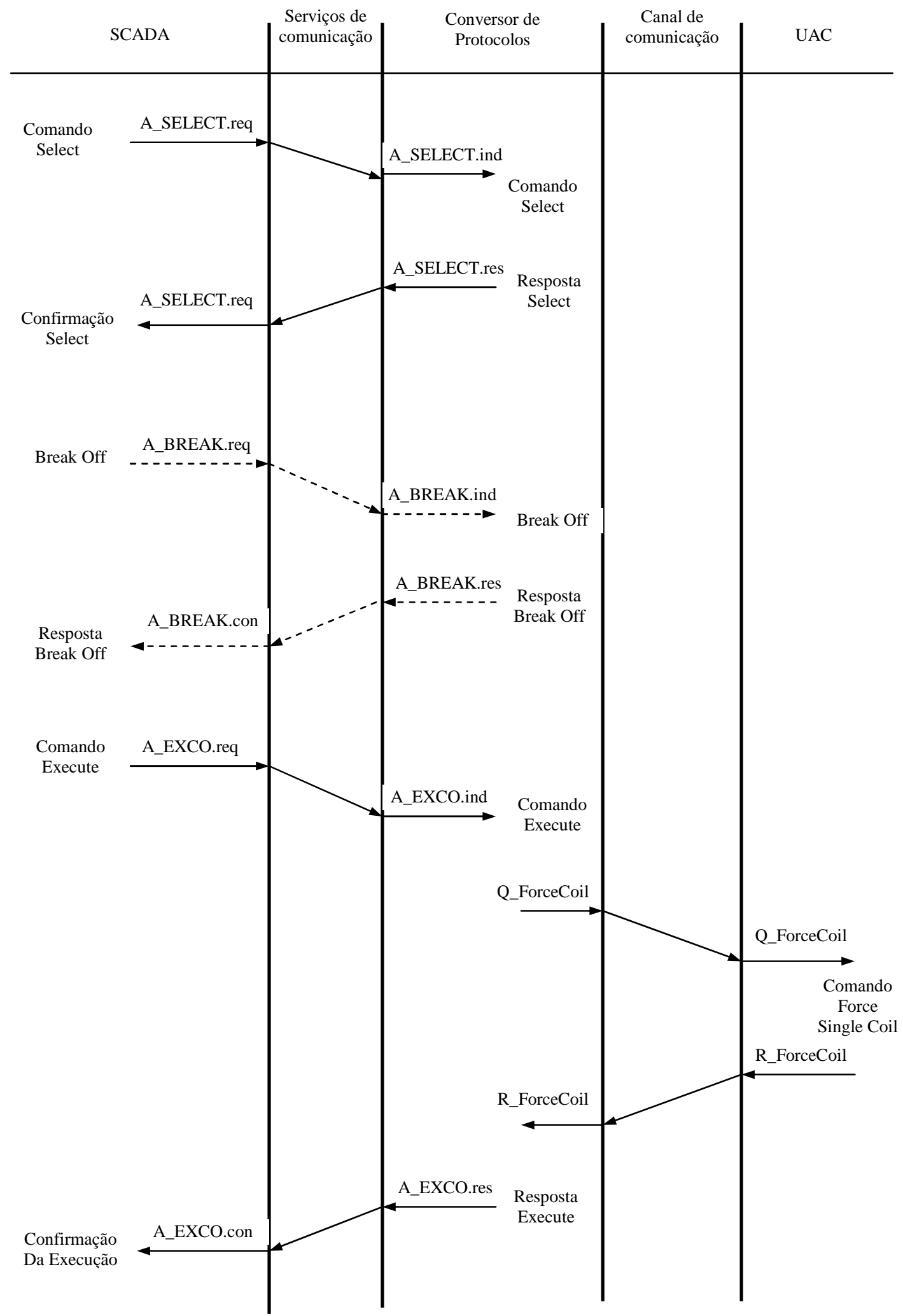

Figura 18 - Sequência Request-Responde para Telecomando baseado em [7] 
ponto, o envio da solicitação do comando a ser executado e a resposta de confirmação da execução do mesmo (SBO-Select Before Operate). No protocolo Modbus o comando é executado diretamente sem a necessidade de seleção do ponto a ser comandado. O detalhamento dos procedimentos será realizado no capítulo 4.

\section{1) Conversão IEC 60870 - Modbus}

Quando da conversão das mensagens IEC 60870 em Modbus e vice-versa os campos que contém informações sobre o endereço da UAC e o código da função a ser realizada são os de maior importância, pois a faixa de valores possíveis para cada um não são compatíveis.

O campo para endereçamento de UACs no protocolo IEC 60870-5 admite os valores de 1 até 65534 quando da utilização de frames de tamanho variável e de 1 a 254 quando da utilização de frames de tamanho fixo. No protocolo Modbus o mesmo campo admite os valores de 1 até 247 . O endereço para envio de mensagens para todas as UAC(global) no protocolo IEC 60870-5 é 65535 para frames de tamanho variável e 255 para frames de tamanho fixo, enquanto que no protocolo Modbus é 0(zero). Para a implementação de um conversor de protocolos pode-se utilizar as eguintes soluções de conversão:

a) contruir uma tabela que relacione os endereços IEC 60870-5 com os respectivos endereços Modbus, de acordo com a específicação de cada sistema implementado.

b) Adotar na estação de controle os endereços iniciais de 1 a 247 como sendo endereços reservados para endereçar UAC Modbus em um sistema específico.

Neste trabalho foi adotada a solução (b), considerando ainda que o conversor de protocolos realiza comunicação com apenas uma UAC, com correspondência direta dos endereços IEC 60870-5 e 1 a 247 para os endereços Modbus de 1 a 247 e a conversão do endereço 255 para 0(zero) realizada pelo conversor de protocolos. 
O campo de código de função IEC 50870-5 será mapeado para o campo de função Modbus dentro do conversor de protocolos segundo mostrado nas Tabelas I e II.

O sistema utilizado para funcionar como estação de controle IEC 60870-5 implementa na camada de enlace frames de tamanho fixo para as mensagens utilizadas nas funções de inicialização e telecomando. Os códigos de função especificados na Tabela I_atendem as especificações para o campo de função existente dentro do campo Control Field dos frames de tamanho fixo.

Tabela I- Sequência Request-Responde para Telecomando

\begin{tabular}{|c|c|c|c|c|}
\hline \multicolumn{5}{|c|}{ Campos de Função } \\
\hline Descrição & $\begin{array}{c}\text { IEC 60870- } \\
5-101\end{array}$ & Modbus & Descrição & Sentido \\
\hline Reset remote link & 0 & 08 & Restart Communication & Mestre - escravo \\
\hline User data & 3 & ----- & & Mestre - escravo \\
\hline Request status of link & 9 & ----- & & Mestre - escravo \\
\hline $\begin{array}{c}\text { Request user data } \\
\text { class } 1\end{array}$ & 10 & ----- & & Mestre - escravo \\
\hline $\begin{array}{c}\text { Request user data } \\
\text { class } 2\end{array}$ & 11 & 02,03 & $\begin{array}{c}\text { Read Input Status, } \\
\text { Read Holding Register }\end{array}$ & Mestre - escravo \\
\hline Ack & 0 & ----- & & Escravo - mestre \\
\hline $\begin{array}{l}\text { Nack: message not } \\
\text { accepted }\end{array}$ & 1 & ----- & & Escravo - mestre \\
\hline User data & 8 & ----- & & Escravo - mestre \\
\hline $\begin{array}{l}\text { Nack: request data } \\
\text { not available }\end{array}$ & 9 & ----- & & Escravo - mestre \\
\hline Status of link & 11 & ----- & & Escravo-mestre \\
\hline
\end{tabular}

As repostas ao comando duplo são realizadas através de frames de tamanho variável. Neste caso o código da função é colocado no campo type identification e seu valor mostrado na Tabela II.

Tabela II - Sequência Request-Responde para Telecomando

\begin{tabular}{|c|c|c|c|c|}
\hline \multicolumn{5}{|c|}{ Campos de Função } \\
\hline Descrição & $\begin{array}{c}\text { IEC 60870- } \\
5-101\end{array}$ & Modbus & Descrição & Sentido \\
\hline Double command & 46 & 05 & Force single coil & Escravo - mestre \\
\hline
\end{tabular}




\section{3 - METODOLOGIA DE DESENVOLVIMENTO - LINGUAGEM DE MODELAGEM UNIFICADA (UML)}

\section{1 - Introdução}

A construção da UML teve como principais atores Grady Booch, James Rumbaugh e Ivar Jacobson. Em 1997, a UML foi aprovada como padrão pelo OMG (Object Management Group) [11] que é um consórcio internacional de empresas que define e ratifica padrões na área da orientação a objetos.

A UML é uma linguagem visual utilizada para modelar sistemas computacionais por meio do paradigma da Orientação a Objetos [8]. Através dos elementos gráficos definidos nesta linguagem pode-se construir diagramas que representam diversas perspectivas de um sistema. Cada elemento gráfico possui uma sintaxe (isto é, uma forma pré-determinada de desenhar o elemento) e uma semântica que definem o que significa o elemento e para que ele deve ser utilizado. Além disso, tanto a sintaxe quanto a semântica da UML são extensíveis; o que permite que a UML seja adaptada às características específicas de cada projeto de desenvolvimento. [9]

A UML é independente tanto de linguagens de programação quanto de processos de desenvolvimento. Isso quer dizer que a UML pode ser utilizada para a modelagem de sistemas, não importa qual a linguagem de programação será utilizada na implementação do sistema, ou qual a forma (processo) de desenvolvimento adotada [9].

\section{2 - Visões de um sistema}

O desenvolvimento de um sistema de software demanda que seus desenvolvedores tenham a possibilidade de examinar e estudar esse sistema a partir de diversas perspectivas. Os autores da UML sugerem que um sistema pode ser descrito por cinco visões interdependentes desse sistema.[10] As visões propostas são as seguintes:

Visão de Casos de Uso: descreve o sistema de um ponto de vista externo como um conjunto de interações entre o sistema e os agentes externos ao sistema. 
Visão de Projeto: enfatiza as características do sistema que dão suporte, tanto estrutural quanto comportamental, às funcionalidades externamente visíveis do sistema.

Visão de Implementação: abrange o gerenciamento de versões do sistema, construídas através do agrupamento de módulos (componentes) e subsistemas.

Visão de Implantação: corresponde à distribuição física do sistema em seus subsistemas e à conexão entre essas partes.

Visão de Processo: esta visão enfatiza as características de concorrência (paralelismo), sincronização e desempenho do sistema.

Dependendo das características e da complexidade do sistema, nem todas as visões precisam ser construídas. [9]

\section{3 - Diagramas da UML}

Um processo de desenvolvimento que utilize a UML como linguagem de suporte à modelagem envolve a criação de diversos documentos. Esses documentos podem ser textuais ou gráficos.

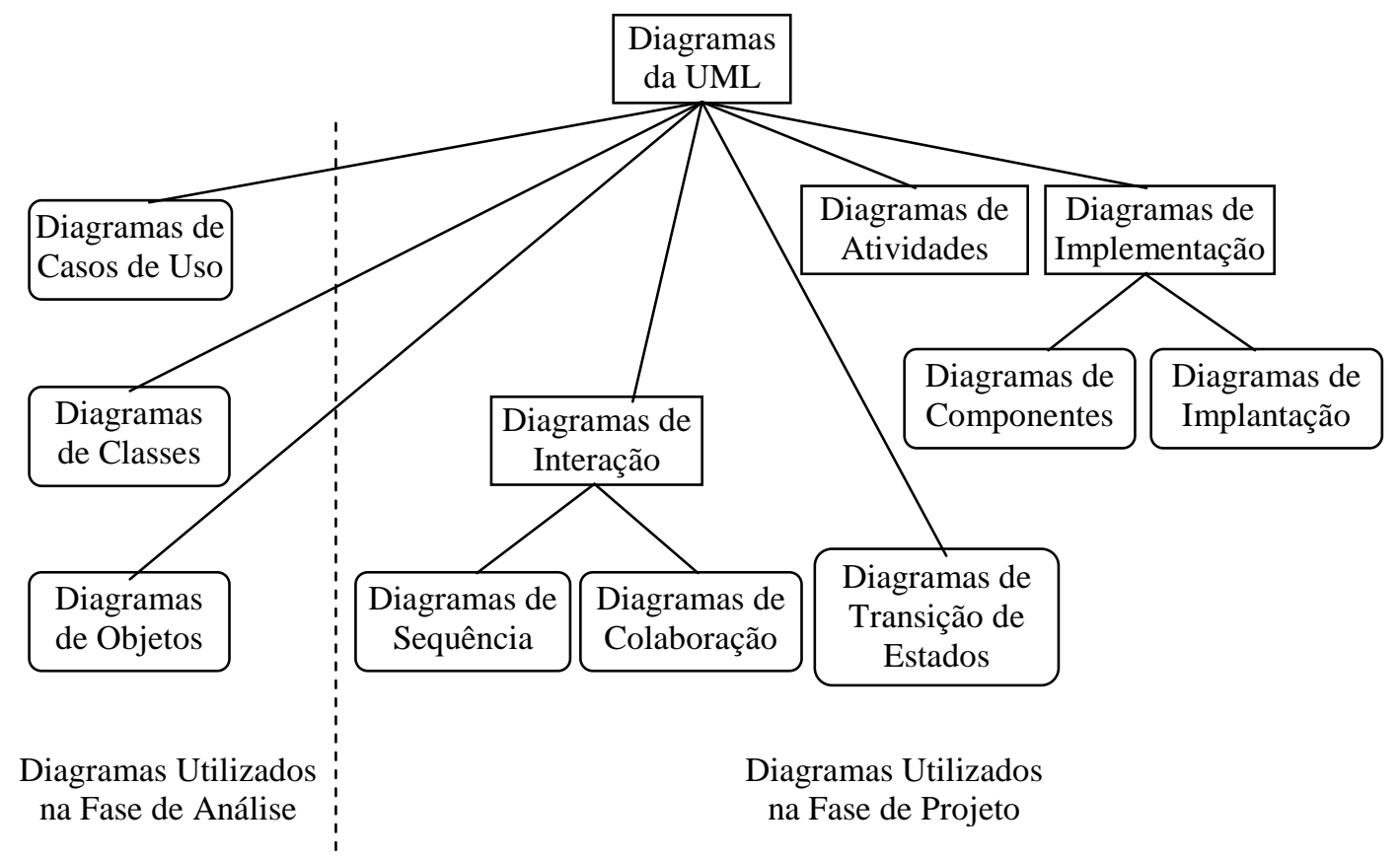

Figura 19 - Diagramas da UML 
Na terminologia da UML, esses documentos são denominados artefatos de software, ou simplesmente artefatos. São os artefatos que compõem as visões do sistema. Os artefatos gráficos produzidos durante o desenvolvimento de um sistema de software são definidos através da utilização dos diagramas da UML. Os diagramas da UML são mostrados na Figura 19. Os retângulos com os cantos retos representam agrupamentos (tipos) de diagramas da UML. Já os retângulos com os cantos arredondados representam os diagramas propriamente ditos [9].

Cada diagrama da UML analisa o sistema, ou parte dele sob uma determinada ótica, é como o sistema fosse modelado em camadas, sendo que alguns diagramas enfocam o sistema de forma mais geral, apresentando uma visão externa do sistema, enquanto outros oferecem uma visão de uma camada mais profunda do software, apresentando um enfoque mais técnico ou ainda visualizando apenas uma característica específica do sistema ou de um determinado processo [8].

\section{4 - A UML na Implementação do Conversor de Protocolos}

Devido às características particulares dos protocolos de comunicação e sua exatidão nas ações a serem executadas, torna-se suficiente realizar a análise e o projeto do conversor de protocolos baseado apenas nos diagramas de Casos de Uso, Diagramas de Classes e Diagramas de Interação (Seqüência).

\section{5 - Modelagem de Casos de Uso}

O modelo de casos de uso é uma representação das funcionalidades externamente observáveis do sistema e dos elementos externos ao sistema que interagem com ele. Na verdade, o modelo de casos de uso molda os requisitos funcionais do sistema. Este modelo é bastante importante, pois direciona diversas tarefas posteriores do ciclo de vida do sistema de software.

\subsection{1 - Modelo de casos de uso}

O modelo de casos de uso de um sistema é composto de casos de uso, de atores e de relacionamentos entre estes. 


\subsubsection{1 - Casos de uso}

Um caso de uso é a especificação de uma sequência de interações entre um sistema e os agentes externos que utilizam esse sistema. Um caso de uso deve definir o uso de uma parte da funcionalidade de um sistema, sem revelar a estrutura e o comportamento interno desse sistema. Um caso de uso representa quem faz o que (interage) com o sistema, sem considerar o comportamento interno do sistema [9]. Cada caso de uso deve ser definido através da descrição narrativa das interações que ocorrem entre o(s) elemento(s) externo(s) e o sistema. A UML não define o formato e o grau de abstração a serem utilizados na descrição de um caso de uso. Conseqüentemente, há vários formatos de descrição propostos na literatura, assim como vários são os graus de abstração utilizados. Os casos de uso são formados por atores, que são elementos externos que interagem com o sistema. A Figura 20 mostra um exemplo.

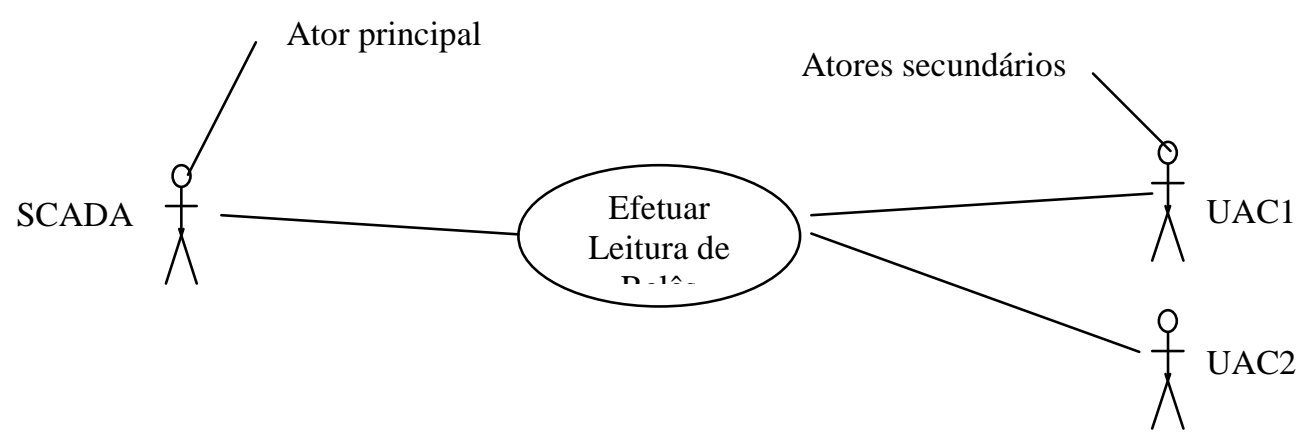

Figura 20 - Representação de um Caso de Uso

\section{6 - Modelagem de Classes de Domínio}

Externamente ao sistema, os atores visualizam resultados de produzidos pelo sistema. Internamente, os objetos do sistema colaboram uns com os outros para produzir os resultados visíveis de fora. Essa colaboração pode ser vista sob o aspecto estrutural estático e sob o aspecto dinâmico [9].

$\mathrm{O}$ aspecto estrutural estático de uma cooperação permite compreender como o sistema está estruturado internamente para que as funcionalidades externamente visíveis sejam produzidas. Esse aspecto é dito estático porque não apresenta informações sobre como os objetos do sistema interagem no decorrer do tempo. Também é dito estrutural porque a estrutura das classes de objetos e as relações entre elas são repre- 
sentadas. Os aspectos estático e dinâmico de um sistema não são independentes. A construção de um serve para adicionar detalhes no outro.

O diagrama da UML utilizado para representar a descrição do aspecto estrutural estático de um sistema orientado a objetos é o diagrama de classes. O modelo de classes é composto do diagrama de classes e da descrição textual associada.

\subsection{1 - Modelo de classes}

É importante notar que o modelo de classes evolui durante as iterações do desenvolvimento do sistema. À medida que o sistema é desenvolvido, o modelo de classes é incrementado com novos detalhes. Há três níveis sucessivos de abstração pelos quais o modelo de classes passa. Esses níveis são: domínio, especificação e implementação.

O modelo de classes de domínio representa as classes no domínio do problema a ser resolvido. Este modelo é construído na fase de análise. Por definição, um modelo de classes de domínio não leva em consideração restrições inerentes à tecnologia a ser utilizada na solução de um problema.

O modelo de classes de especificação é uma extensão do modelo de classes de domínio. Essa extensão é feita através da adição de detalhes específicos conforme a solução de software escolhida. Além disso, nesse nível são definidas novas classes necessárias para desenvolver a solução do problema.

O modelo de especificação é construído na atividade de projeto do desenvolvimento de uma iteração do desenvolvimento.

O modelo de classes de implementação corresponde à implementação das classes em alguma linguagem de programação, normalmente uma linguagem orientada a objetos.

\subsection{2 - Diagrama de classes}

O diagrama de classe é utilizado na construção do modelo de classes desde o nível de análise até o nível de especificação.

\subsubsection{1 - Elementos do diagrama de classes}

Uma classe é representada através de uma "caixa" com, no máximo, três compartimentos exibidos. No primeiro compartimento é exibido o nome da classe. 
Por convenção, esse nome é apresentado no singular e com as palavras componentes começando por maiúsculas. No segundo compartimento, são declarados os atributos e no terceiro compartimento, são declaradas as operações. As possíveis notações da UML para representar classes são apresentadas na figura abaixo. O grau de abstração desejado em um dado momento do desenvolvimento do modelo de classes direciona a utilização de uma ou outra notação. A Figura 21 mostra as possíveis notações para uma classe UML.

\begin{tabular}{|c|c|c|c|}
\hline Nome da Classe & Nome da Classe & Nome da Classe & \\
\hline & Lista de atributos & lista de operações & $\begin{array}{l}\text { lista de atributos } \\
\text { lista de operações }\end{array}$ \\
\hline
\end{tabular}

Figura 21 - Notações utilizadas para a representação de classes.

Os atributos correspondem à descrição dos dados armazenados pelos objetos de uma classe. A cada atributo de uma classe está associado um conjunto de valores que esse atributo pode assumir. As operações correspondem à descrição das ações que os objetos de uma classe sabem realizar. Ao contrário dos atributos (para os quais cada objeto tem o seu próprio valor), objetos de uma classe compartilham as mesmas operações. O nome de uma operação normalmente contém um verbo e um complemento, e terminam com um par de parênteses [9].

\section{7 - Modelagem de Interações (Diagramas de Sequência)}

O modelo de casos de uso nada informa sobre qual deve ser o comportamento interno do sistema para que uma determinada funcionalidade seja realizada. Ou seja, para que um caso de uso seja realizado, produzindo um resultado de valor para o ator, quais são as operações que devem ser executadas internamente ao sistema? A que classes essas operações pertencem? Quais objetos participam da realização deste caso de uso? Essas perguntas não encontram resposta no modelo de casos de uso de um sistema, não importa o quão detalhado esse modelo seja.

O modelo de classes de domínio fornece uma visão estrutural e estática inicial do sistema. No entanto, de que forma os objetos colaboram para que um determinado caso de uso seja realizado? Em que ordem as mensagens são enviadas durante essa realização? Que informações precisam ser enviadas em uma mensagem de um objeto 
a outro? Será que há responsabilidades ou mesmo classes que ainda não foram identificadas? O modelo de classes de domínio não responde a essas perguntas.

O objetivo desses modelos é fornecer um entendimento do problema correspondente ao sistema de software a ser desenvolvido.

Para responder às questões levantadas nos parágrafos anteriores, o modelo de interações do sistema precisa ser criado. Esse modelo representa as mensagens trocadas entre os objetos para a execução de cenários dos casos de uso do sistema.

Através da construção do modelo de interações, as classes, responsabilidades e colaboradores identificados anteriormente podem ser validados. Esse modelo permite ainda refinar o modelo de classes de domínio, pois as operações de cada classe são identificadas na construção do modelo de interações.

\subsection{1 - Interações através de mensagens}

O princípio básico da interação entre objetos é o conceito de mensagem. Uma mensagem é uma solicitação de execução de uma operação em outro objeto. Um sistema de software orientado a objetos pode ser visto como uma rede de objetos. As funcionalidades desse sistema são realizadas por seus objetos componentes, que só podem interagir através de mensagens [9].

Uma mensagem representa a requisição de um objeto remetente a um objeto receptor para que este último execute alguma operação definida para sua classe. Essa mensagem deve conter informação suficiente para que a operação do objeto receptor possa ser executada [9].

\subsubsection{1 - - Tipos de mensagens}

Os tipos de mensagens definidos pela UML [9] são:

Uma mensagem simples é utilizada quando a natureza da mensagem não é relevante. Esse é o tipo de mensagem mais utilizado na maioria das vezes.

Uma mensagem síncrona indica que o objeto remetente espera que o objeto receptor processe a mensagem antes de recomeçar o seu processamento. Ou seja, o remetente fica bloqueado até que o receptor termine de atender à requisição.

Uma mensagem assíncrona é aquela na qual o objeto remetente não espera a resposta para prosseguir com o seu processamento. 


\subsection{2 - - Sintaxe da UML e especificação de mensagens}

Cada mensagem é representada graficamente por uma seta cujo sentido é do objeto remetente para o objeto receptor. As setas possuem rótulos que especificam a mensagem sendo enviada. Dessa forma, esse rótulo pode ser visto como a especificação das informações que são passadas pelo objeto remetente. A Figura 22 mostra um exemplo de diagrama de sequência.

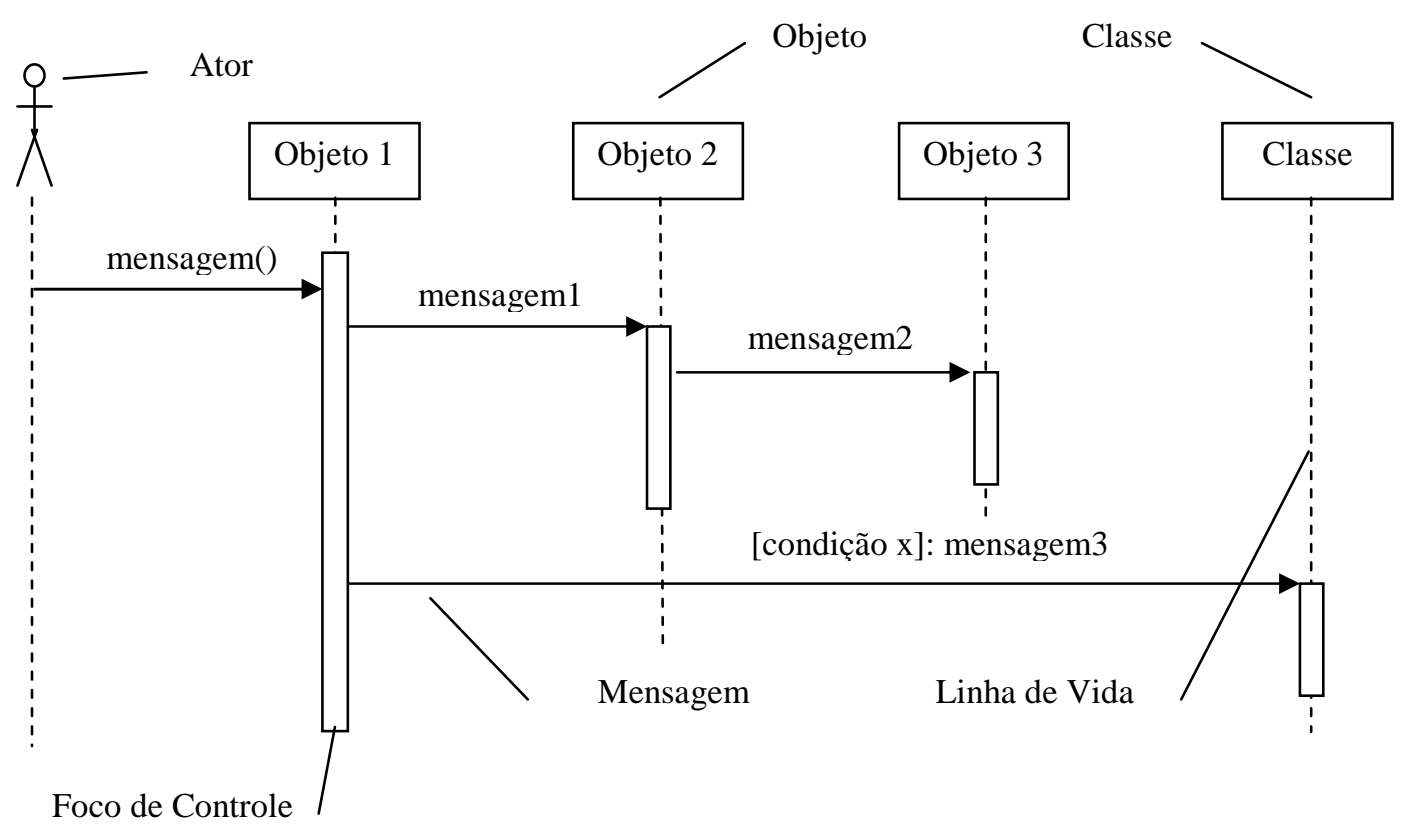

Figura 22 - Construção de um Diagrama de Seqüência.

O diagrama de seqüência tem como foco principal demonstrar como as mensagens são enviadas entre os objetos ao longo do tempo. Algumas vezes é necessário indicar que uma mensagem só será enviada se atender a uma condição lógica (valor verdadeiro ou falso). Para a representação desta condição a sintaxe a ser seguida para a mensagem é: [condição]: mensagem() .

\section{8 - Modelagem de Estados}

Cada objeto participante de um sistema de software orientado a objetos se encontra em um estado particular. Um objeto muda de estado quando acontece algum evento interno ou externo ao sistema. Quando um objeto muda de um estado para outro, diz-se que ele realizou uma transição entre estados. Os estados e as transições de 
estado de um objeto constituem o seu ciclo de vida. Quando da sua transição de um estado para outro, um objeto normalmente realiza determinadas ações dentro do sistema. Cada objeto pode passar por um número finito de estados durante a sua vida. Quando um objeto transita de um estado para outro, significa que o sistema no qual ele está inserido também está mudando de estado.

Através da análise das transições entre estados dos objetos de um sistema de software, pode-se prever todas as possíveis operações realizadas, em função de eventos que possam ocorrer [9].

O diagrama UML utilizado para realizar essa análise é o diagrama de transição de estados. Esse diagrama permite descrever o ciclo de vida de objetos de uma classe, os eventos que causam a transição de um estado para outro e a realização das operações resultantes. Ele é também utilizado para obter uma visão dinâmica do sistema. No entanto, diferentemente dos diagramas de interação que descrevem o comportamento de objetos de classes diferentes, um diagrama de transição de estados descreve o comportamento de objetos de uma única classe.

Os diagramas de estados são definidos apenas para as classes que possuam um número definido de estados conhecidos, e onde o comportamento das classes de objetos é afetado e modificado pelos diferentes estados. Nessas classes um diagrama de transição de estado pode ser utilizado para enfatizar eventos que resultam em mudanças de estado [9]. A Figura 23 mostra um exemplo de diagrama de transição de estados e seus elementos básicos.

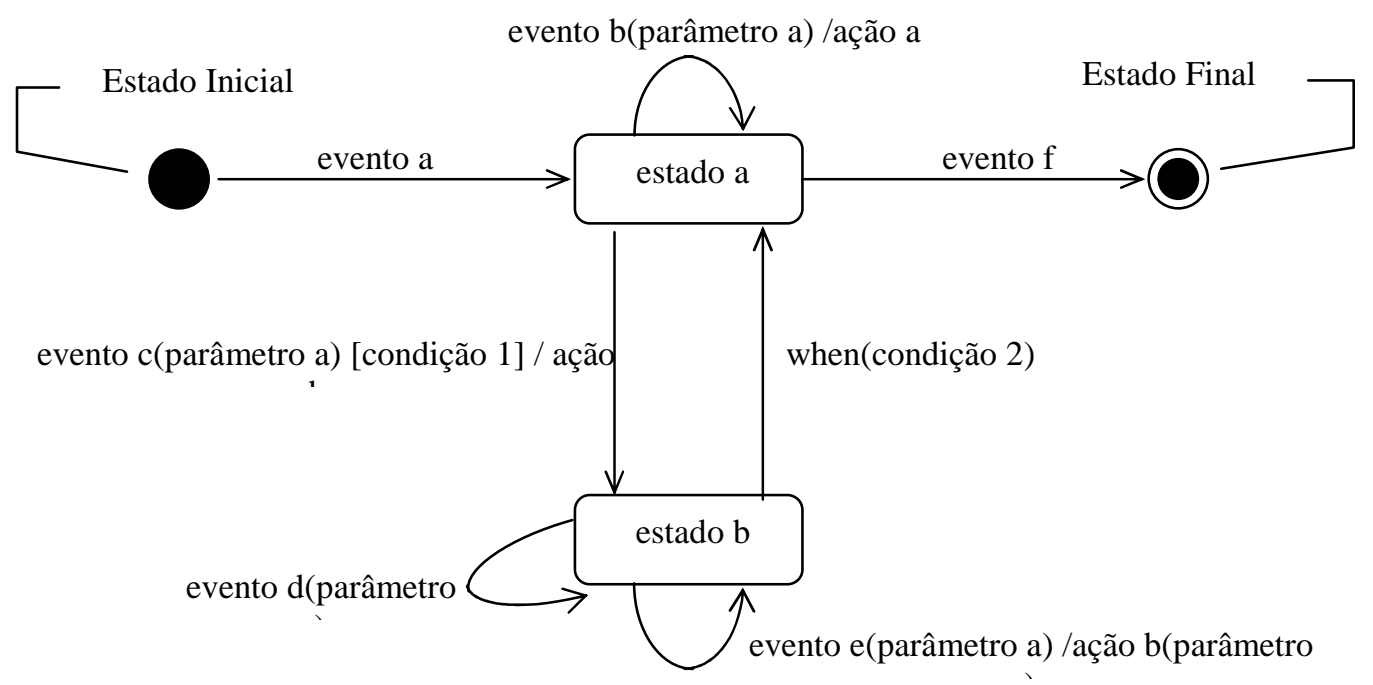

Figura 23 - Elementos de um diagrama de transição de estados. 


\subsection{1 - Elementos de um Diagrama de transição de estados}

Alguns elementos básicos de um diagrama de transição de estados são os estados e as transições. Associados a eles, estão os conceitos de evento, ação e atividade. Pode conter ainda elementos tais como as transações internas, estados aninhados e estados concorrentes.

Estado: uma situação na vida de um objeto durante a qual ele satisfaz alguma condição ou realiza alguma atividade. Cada estado de um objeto é normalmente determinado pelos valores dos seus atributos e (ou) pelas ligações com outros objetos.

Transições: um estado está associado a outro por meio das transições. Um transição pode ser rotulada com uma expressão descrita por evento(listaparâmetros) [guarda] / ação.

Evento: é algo que acontece em algum ponto no tempo e que pode modificar o estado de um objeto.

Condição de guarda (guarda): é uma expressão de valor lógico. A transição no qual foi definida uma condição de guarda é disparada somente se o evento associado ocorre e a condição de guarda é verdadeira. Se uma condição não tiver condição de guarda, ela sempre será disparada quando o evento ocorrer.

Ação: é uma expressão que pode ser definida em termos dos atributos, operações ou associações de uma classe. Pode corresponder à execução de uma operação. As ações podem ser especificadas para serem executadas em determinados momentos da existência do objeto:

Cláusula "entry", usada para especificar ações a serem realizadas quando o objeto entra em um estado.

Cláusula "exit", usada para especificar ações a serem realizadas quando o objeto sai de um estado.

Cláusula " $d o$ ", usada para definir alguma atividade quando o objeto passa para um determinado estado. Uma atividade pode ser interrompida, uma ação não. 


\section{4 -DESENVOLVIMENTO DAS FUNÇÕES DE CONVERSÃO DOS PROTOCOLOS UTILIZANDO A UML}

Para o projeto da implementação das funções de conversão dos protocolos serão utilizados os casos de uso, diagramas de classes de domínio e de especificação, diagramas de seqüência e diagramas de estados.

\section{1 - Casos de Uso}

Serão estudadas as seguintes funções de conversão de protocolos: inicialização do Sistema SCADA (COS), leitura de valores digitais, leitura de valores analógicos, escrita de valores digitais (telecomando). Os casos de uso devem ser implementados considerando como atores um sistema SCADA e uma unidade de aquisição e controle (UAC). Será utilizada a forma de descrição numerada para descrever os casos de uso. Na descrição dos casos de uso o termo IEC 60870 será utilizado para representar o protocolo IEC 60870-5-101.

\subsection{1 - Caso de Uso 1: Inicialização}

(1) Sistema SCADA envia mensagem no formato IEC 60870 ao conversor, solicitando o status do link de comunicação.

(2) a) Se link OK! conversor responde com mensagem de link OK!. Segue para o passo (3).

b) Se link não OK! Conversor responde com NACK. Retorna ao passo (1). obs: Sempre que O Sistema SCADA ou UAC inicia comunicação com o conversor e não houver sucesso haverá uma mensagem de NACK (por isto este aspecto será omitido na continuação do texto

(3) Sistema SCADA envia mensagem no formato IEC 60870 ao conversor, solicitando o reset do link de comunicação.

(4) Conversor envia para a UAC mensagem no formato Modbus solicitando a reinicialização da porta de comunicação serial.

(5) UAC envia para o conversor mensagem no formato Modbus, com a informação de que a porta de comunicação foi reinicializada.

(6) a) Se passo (5) OK! conversor responde para o Sistema SCADA com mensagem de link OK no formato IEC 60870. Segue para o passo (7). 
b) Se passo (5) não OK! Conversor responde para o sistema SCADA com mensagem NACK. Retorna ao passo (1).

(7) Sistema SCADA envia mensagem no formato IEC 60870 ao conversor, solicitando os dados de classe 1 (dados de transmissão espontânea).

(8) Conversor responde com mensagem indicando nenhum dado a transmitir.

(9) Sistema SCADA envia mensagem no formato IEC 60870 ao conversor, solicitando os dados de classe 2 (dado de transmissão cíclica).

(10) Conversor responde com mensagem indicando nenhum dado a transmitir.

(11) Sistema SCADA está inicializado e entra em processo de interrogação geral.

No caso dos passos (7) e (9) do caso de uso acima, o conversor deve responder que não possui dados a transmitir, pois uma UAC Modbus não implementa dados organizados em classes e não é possível a transmissão espontânea de dados.

\subsection{2 - Caso de Uso 2: Leitura de Entradas Digitais}

(1) Sistema SCADA envia mensagem em formato IEC 60870 ao conversor, solicitando a leitura de entradas digitais.

(2) Conversor converte mensagem no formato IEC 60870 para o formato Modbus.

(3) Conversor envia para UAC mensagem no formato Modbus solicitando a leitura de entradas digitais.

(4) UAC envia para o conversor mensagem no formato Modbus, com a informação solicitada.

(5) Conversor converte as informações recebidas para o formato IEC 60870.

(6) Conversor envia para o Sistema SCADA mensagem no formato IEC 60870 contendo as informações sobre entradas digitais.

\subsection{3 - Caso de Uso 3: Leitura de Entradas Analógicas}

(1) Sistema SCADA envia mensagem em formato IEC 60870 ao conversor, solicitando a leitura de entradas analógicas. 
(2) Conversor converte mensagem no formato IEC 60870 para o formato Modbus.

(3) Conversor envia para UAC mensagem no formato Modbus solicitando a leitura de entradas analógicas.

(4) UAC envia para o conversor mensagem no formato Modbus, com a informação solicitada.

(5) Conversor converte as informações recebidas para o formato IEC 60870.

(1) Conversor envia para o Sistema SCADA mensagem no formato IEC 60870 contendo as informações sobre entradas analógicas.

\subsection{4 - Caso de Uso 4: Escrita de Valor Digital (Telecomando)}

(1) Sistema SCADA envia mensagem em formato IEC 60870 ao conversor, selecionando ponto a receber o comando ON/OFF.

(2) Conversor responde com ACK.

(3) Sistema SCADA envia mensagem solicitando dados de classe 1 ou 2 em formato IEC 870.

(4) Conversor envia para o Sistema SCADA mensagem no formato IEC 60870 confirmando a seleção do ponto.

(5) Se ocorrer a desistência de efetuar o comando (break off) Sistema SCADA envia para conversor mensagem correspondente. Senão segue para o passo (9).

(6) Conversor responde com um ACK.

(7) Sistema SCADA envia mensagem solicitando dados de classe 1 ou $2 \mathrm{em}$ formato IEC 870.

(8) Conversor envia para o Sistema SCADA mensagem no formato IEC 60870 confirmando a desistência de efetuar comando.

(9) Sistema SCADA envia mensagem em formato IEC 60870 ao conversor, para execução do comando selecionado anteriormente.

(10) Conversor responde com ACK.

(11) Sistema SCADA envia mensagem solicitando dados de classe 1 ou $2 \mathrm{em}$ formato IEC 870.

(12) Conversor converte mensagem no formato IEC 60870 para o formato Modbus. 
(13) Conversor envia para UAC mensagem no formato Modbus, para a execução do comando.

(14) UAC envia mensagem para o conversor no formato Modbus, com a confirmação da execução do comando.

(15) Conversor converte as informações recebidas para o formato IEC 60870.

(16) Conversor envia para o Sistema SCADA mensagem no formato IEC 60870, com a confirmação da execução do comando.

(17) Sistema SCADA envia mensagem solicitando dados de classe 1 ou $2 \mathrm{em}$ formato IEC 60870.

(18) Conversor responde com mensagem de término da execução do comando.

\subsection{5 - Diagrama de Casos de Uso do Conversor de Protocolos.}

A Figura 24 mostra de forma visual os casos de uso que foram definidos para a implementação da conversão de protocolos.

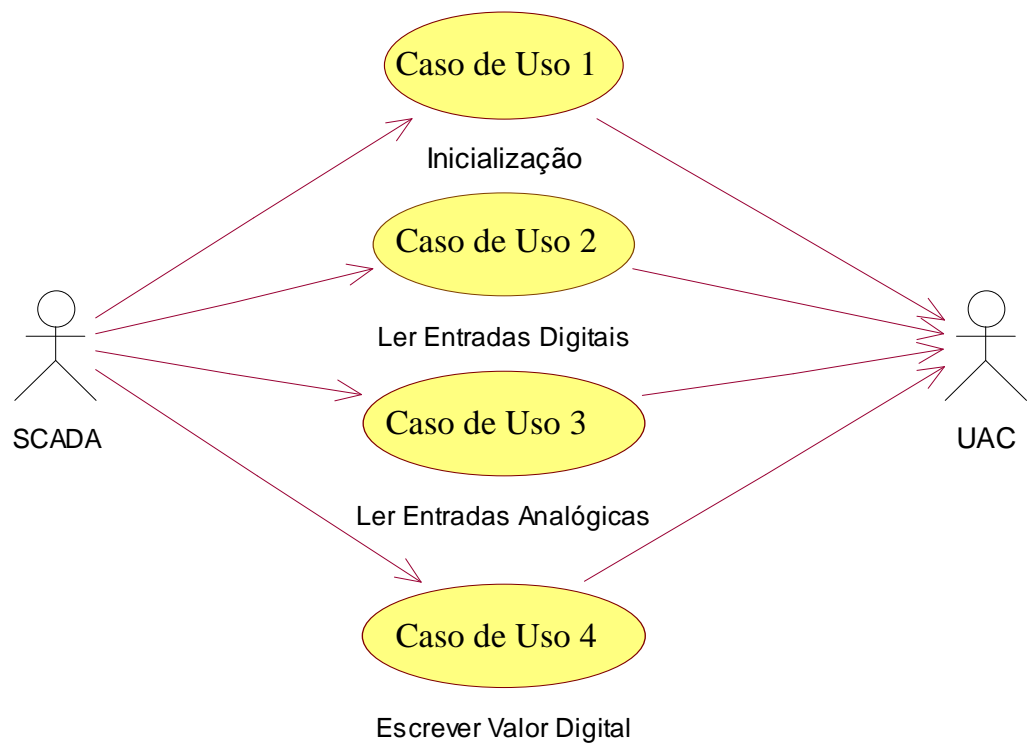

Figura 24 - Casos de Uso Estudados 


\section{2 - Modelos de Classes do Conversor de Protocolos}

\subsection{1 - Modelo de Classes de Domínio}

No modelo de classes de domínio, são especificados as classes e o relacionamento entre elas, buscando representar o funcionamento do sistema.

Os nomes dados as classes de domínio e seu significado são explicados abaixo:

R_FRM_IEC: recebimento de frames IEC.

E_FRM_IEC: envio de frames IEC.

T_FRM_IEC: tratamento de frames IEC.

CV_INIC: conversão de formatos para inicialização.

CV_LD: conversão de formatos para leitura de dados digitais.

CV_LA: conversão de formatos para leitura de dados analógicos.

CV_TC: conversão de formatos para telecomando.

E_MSG_MOD: envio de mensagens Modbus.

R_MSG_MOD: recebimento de mensagens Modbus.

A notação 1...1 (multiplicidade) indica uma associação binária entre as classes, ou seja, a instância de uma classe estará associada a somente uma instância da outra classe. A Figura 25 mostra as classes de domínio para a implementação dos quatro casos de uso 1 e 2 citados no item 4.1.

Associadas ao Caso de Uso 1

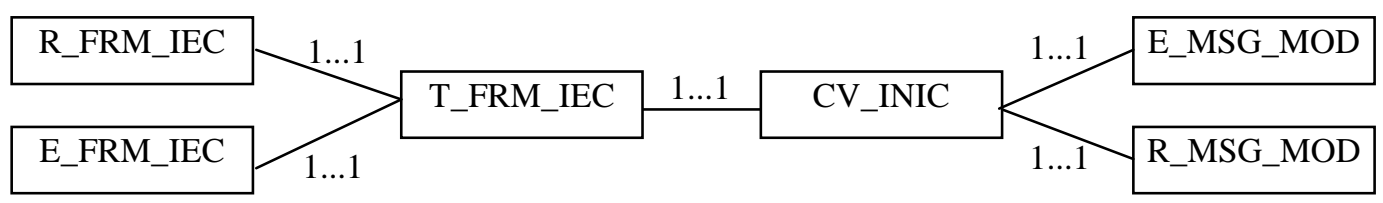

Associadas ao Caso de Uso 2

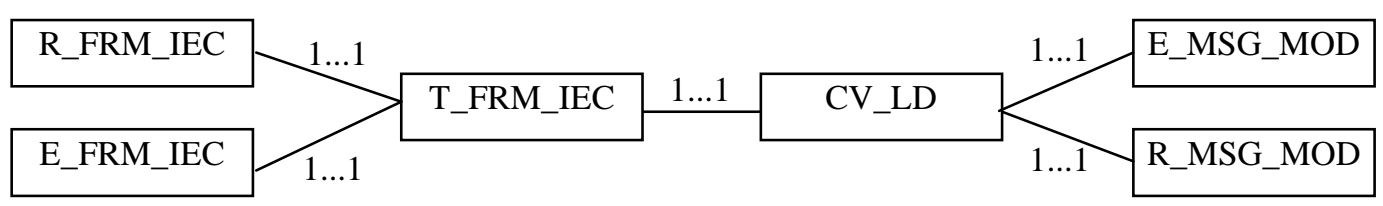

Figura 25 - Classes de domínio da implementação dos casos de uso 1 e 2 
A figura 26 mostra as classes de domínio para a implementação dos quatro casos de uso 3 e 4 citados no item 4.1 .

Associadas ao Caso de Uso 3

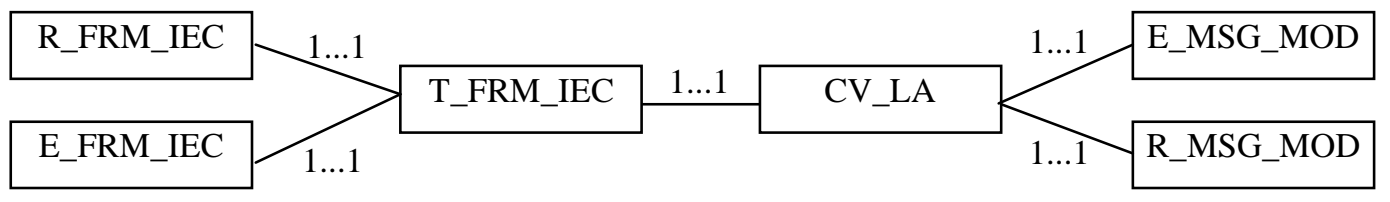

Associadas ao Caso de Uso 4

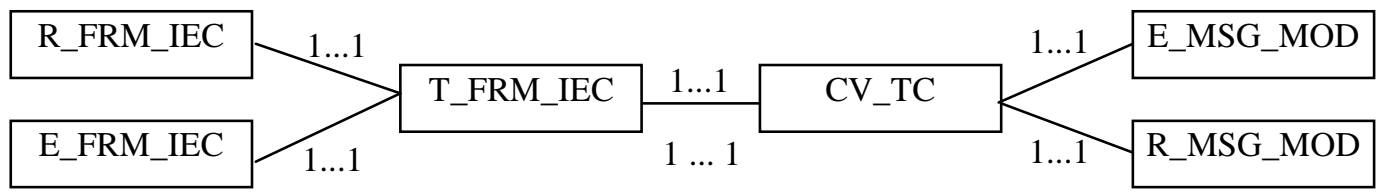

Figura 26 - Classes de domínio da implementação dos casos de uso 3 e 4

\subsection{2 - Modelo de Classes de Especificação}

Neste modelo necessitamos definir para cada uma das classes de domínio especificadas, os atributos de cada classe (por exemplo: endereço da UTR, função realizada, quantidade de dados transmitidos, valor da detecção de erros) e as operações de cada classe (por exemplo: cálculo de checksum, conversão de formatos, etc.). Os três compartimentos que representam uma classe de especificação contém respectivamente: o nome da classe, seus atributos e suas operações (métodos).

A Figura 27 mostra as seis classes envolvidas na inicialização do centro de controle(Sistema SCADA) .

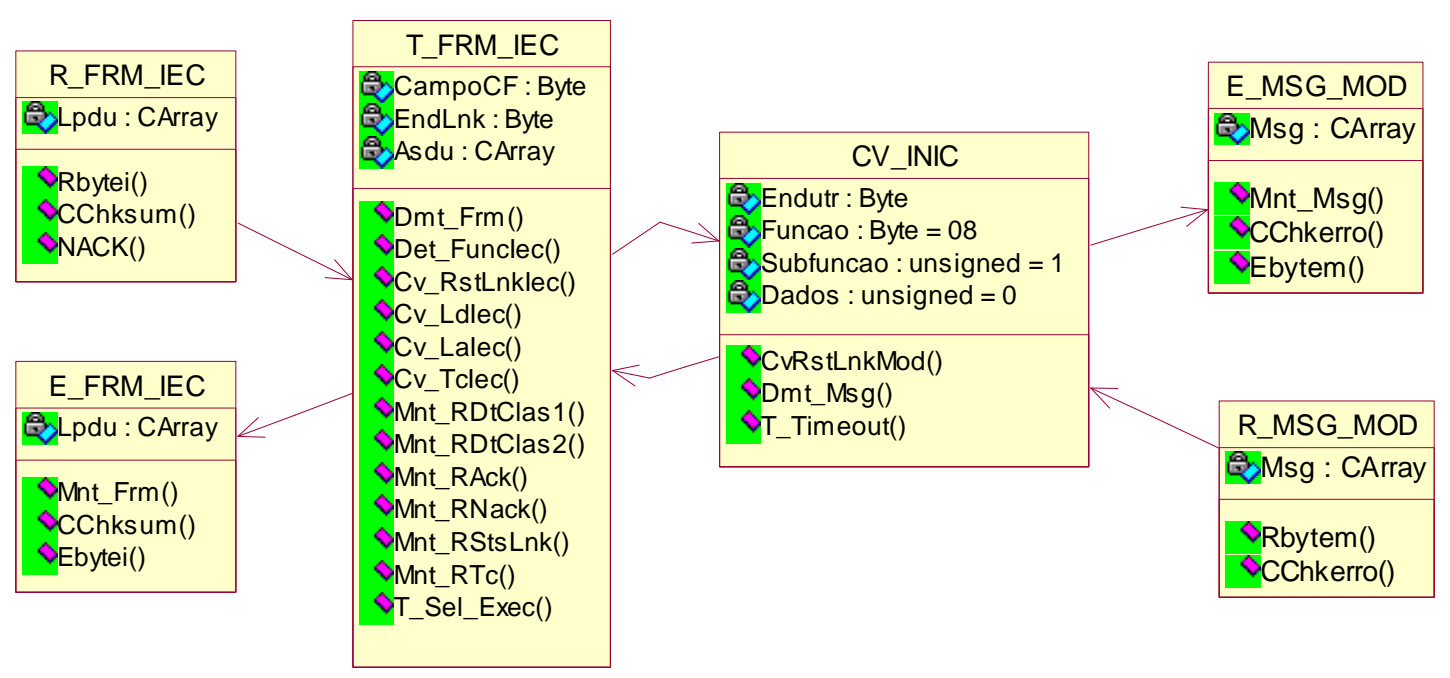

Figura 27 - Classes envolvidas na inicialização do centro de controle 
A Figura 28 mostra as seis classes envolvidas na conversão de uma solicitação de leitura de entradas digitais entre o protocolo IEC 60870 e o protocolo Modbus.

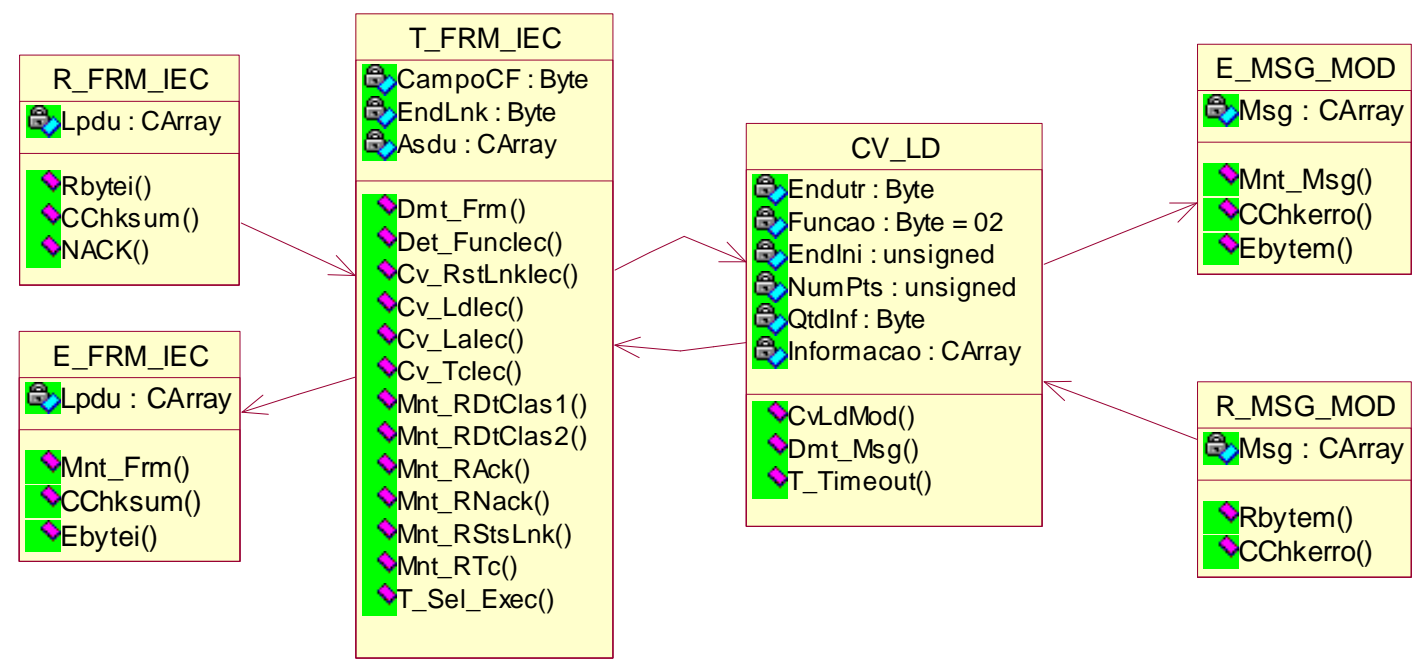

Figura 28 - Classes envolvidas na solicitação de leitura de entradas digitais

A Figura 29 mostra as seis classes envolvidas na conversão de uma solicitação de leitura de entradas analógicas entre o protocolo IEC 60870 e o protocolo Modbus.

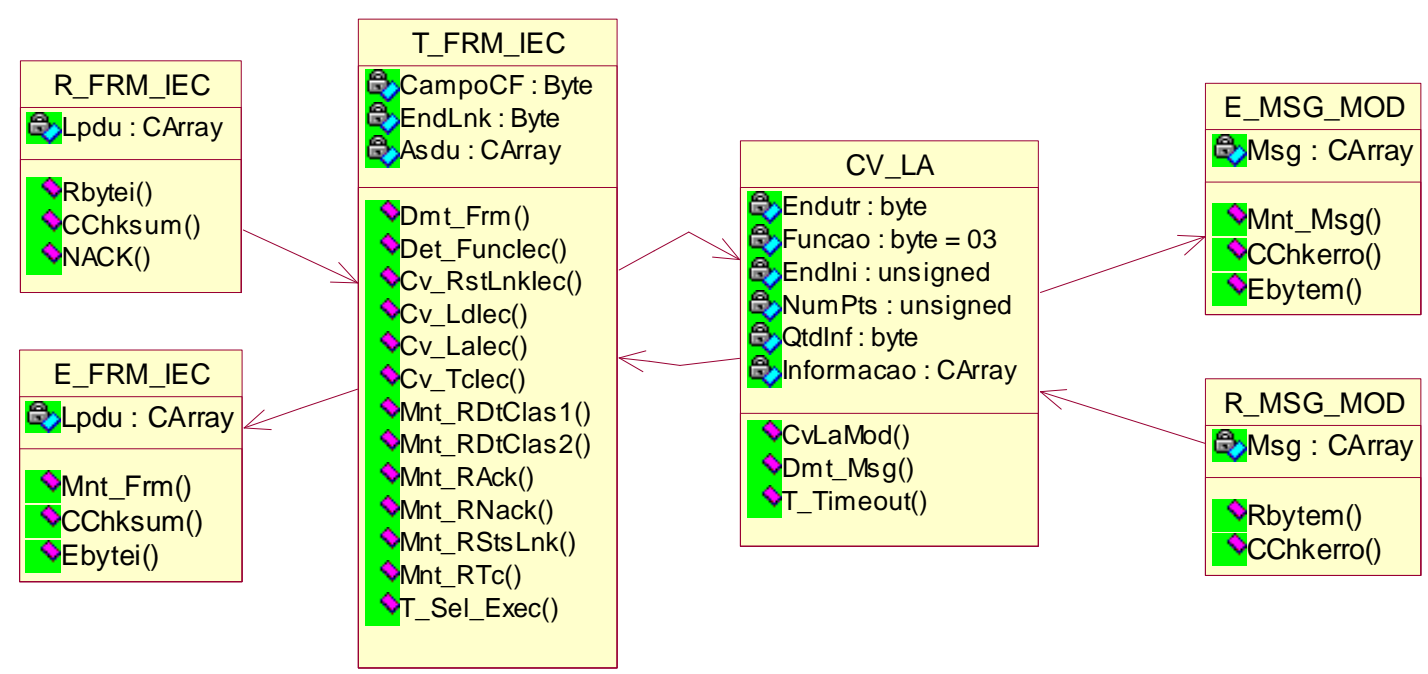

Figura 29 - Classes envolvidas na solicitação de leitura de entradas analógicas

A Figura 30 mostra as seis classes envolvidas na conversão da solicitação de um telecomando entre o protocolo IEC 60870 e o protocolo Modbus. 


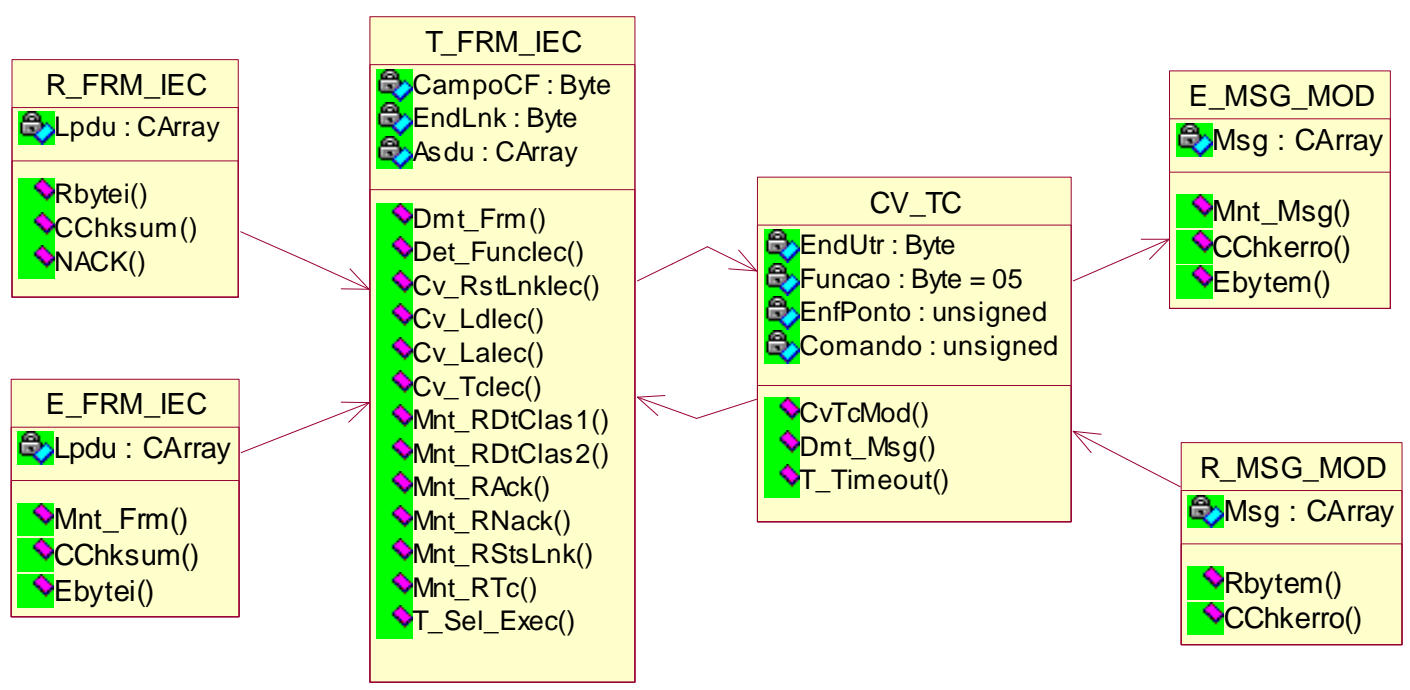

Figura 30 - Classes envolvidas na solicitação de telecomando

\section{3 - Diagramas de Sequência dos Casos de Uso}

No desenvolvimento deste trabalho foi dada ênfase a implementação das funções de inicialização e telecomando. Estas duas funções são das funções estudadas as que apresentam o maior número de mensagens trocadas entre o centro de controle, conversor de protocolos e a UAC. Para uma maior clareza; na representação das trocas de mensagens nos diagramas de sequência, não são mostrados os atores participantes dos casos de 1 (inicialização) e do caso de uso 4 (telecomando). A Figura 31 mostra o diagrama de sequência relativo a inicialização do Sistema SCADA (caso de uso 1). Nele estão representados os objetos que interagem para a realização desta tarefa. 


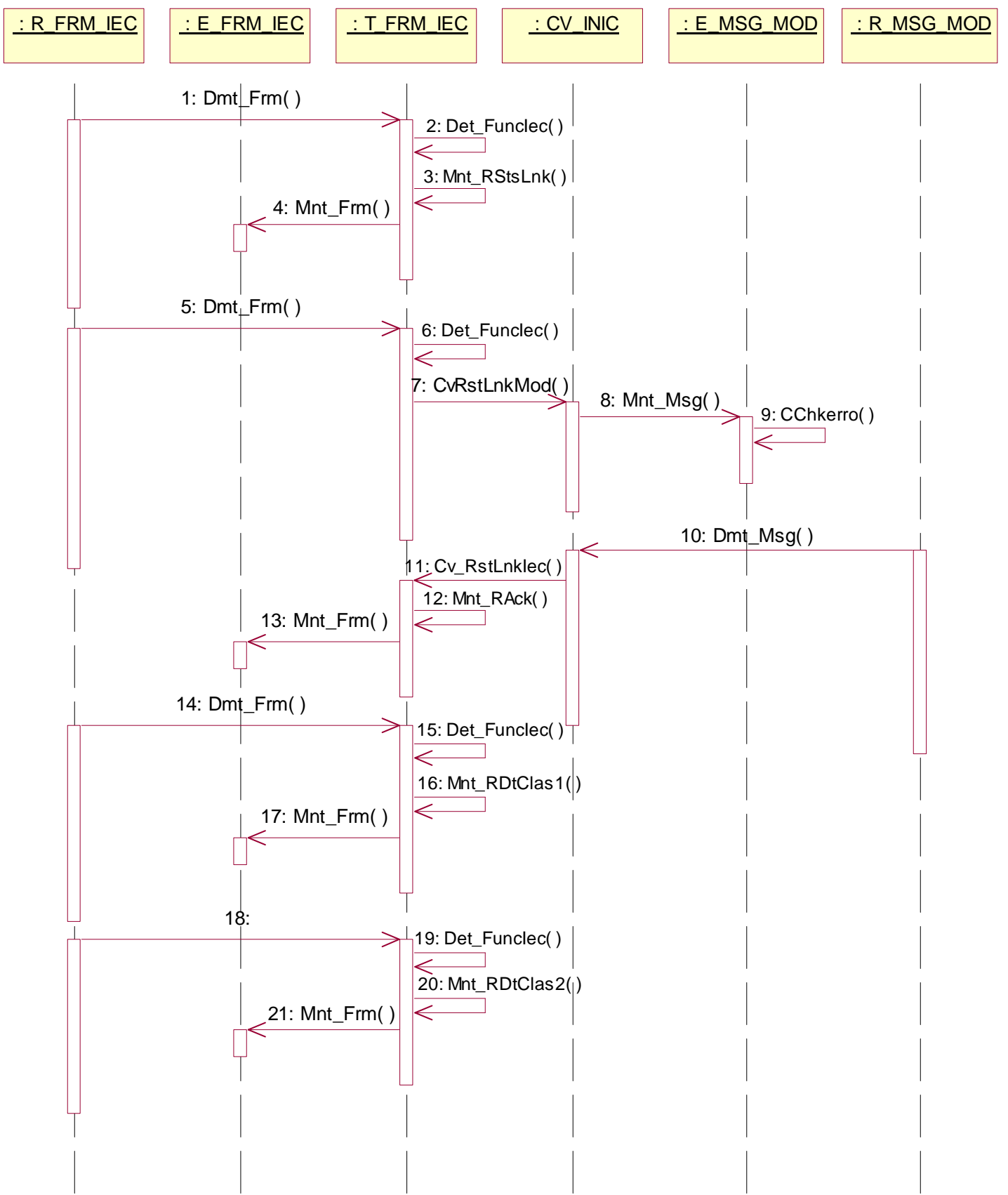

Figura 31 - Diagrama de seqüência para o caso de uso 1 (inicialização)

A Figura 32 mostra o diagrama de sequência relativo a telecomando (caso de uso 4). Nele estão representados os objetos que interagem para a realização desta tarefa. 


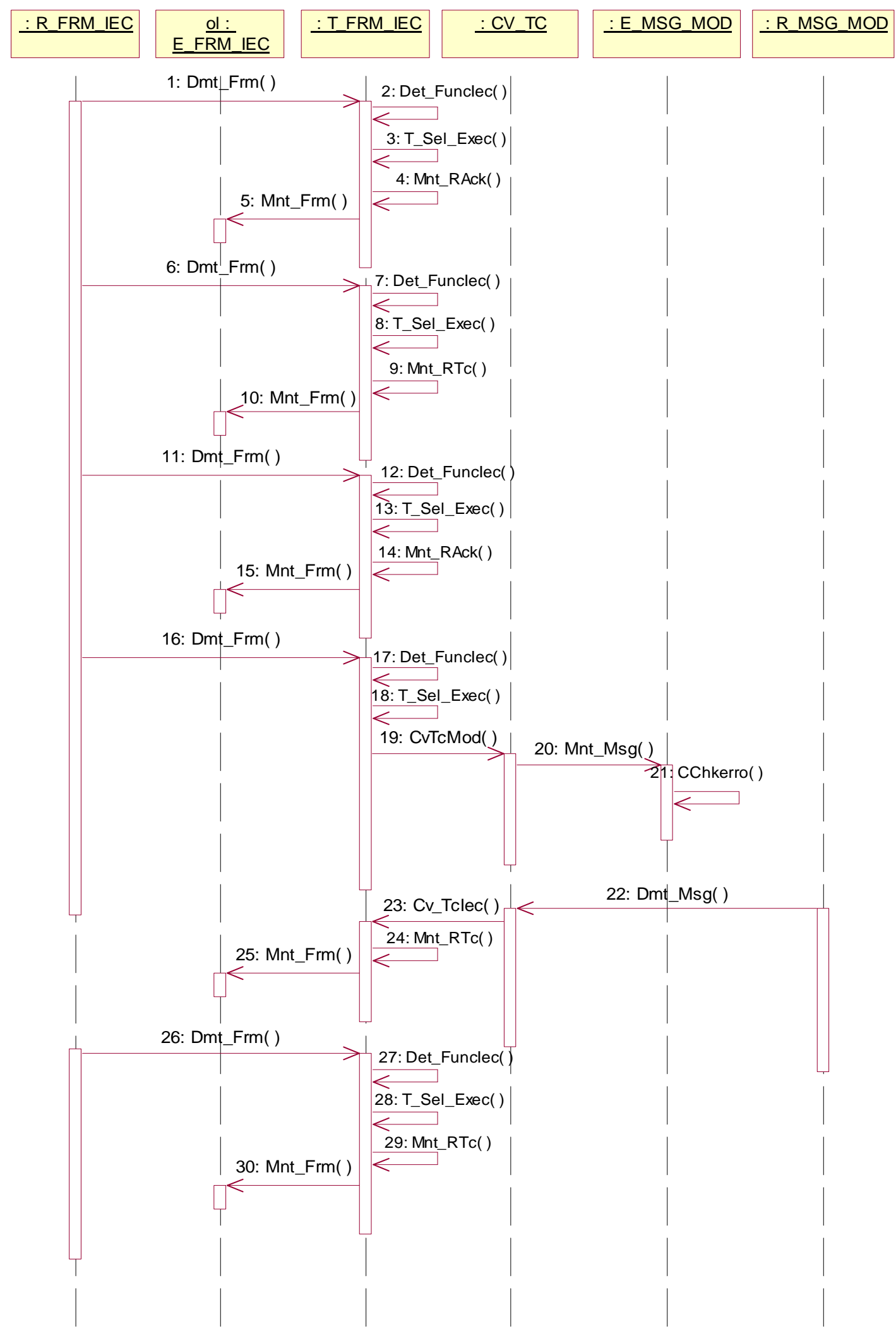

Figura 32 - Diagrama de sequência para o caso de uso 4 (telecomando) 
Os diagramas de sequência permitem a visualização das interações entre os objetos que se relacionam para a realização de um caso de uso. Para a compreensão das atividades e dos estados assumidos por cada objeto, é necessária a análise individual de cada um deles, sendo o diagrama de estados a ferramenta mais adequada para esse fim.

\section{4 - Diagramas de Estado}

Nos diagramas de estado temos a representação dos estados que uma classe instanciada (objeto) pode assumir. Seguindo o que foi adotado no item 4.3 serão mostrados apenas os diagramas de estado das classes que participam dos casos de uso 1 (inicialização) e 4 (telecomando). Desta forma a Figura 33 mostra os estados da classe R_FRM_IEC participante do caso de uso 1. Nas Figuras 34, 35 e 36 temos os diagrama de estados das E_FRM_IEC, E_MSG_MOD e R_MSG_MOD também participantes do caso de uso 1.

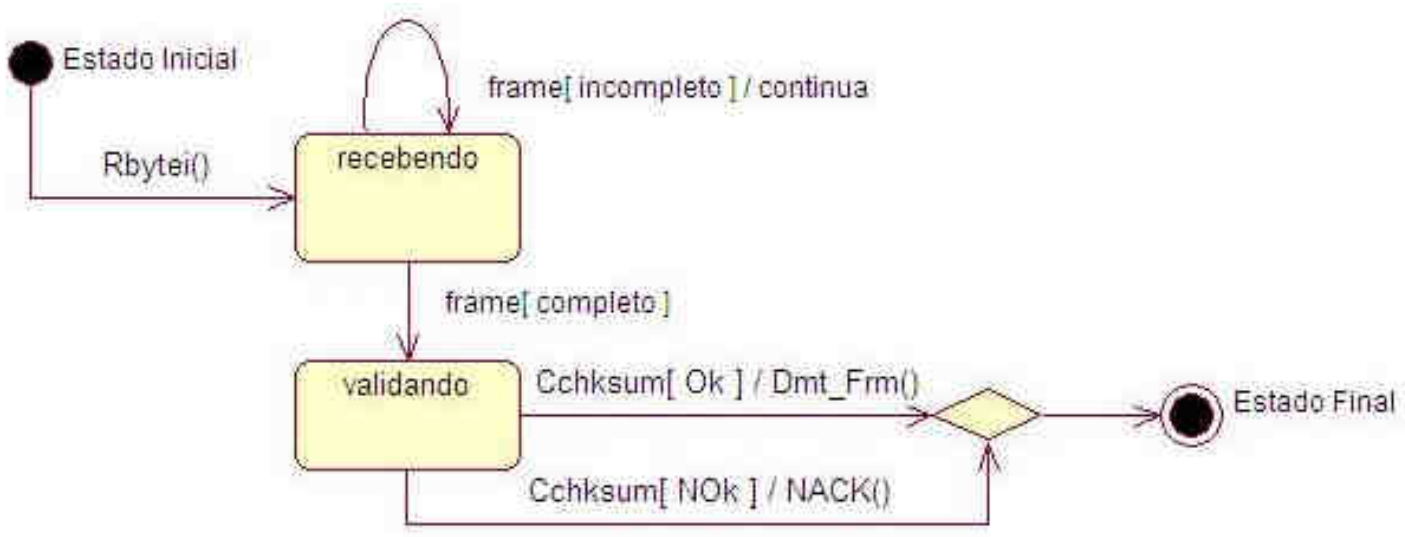

Figura 33 - Diagrama de estados da classe R_FRM_IEC

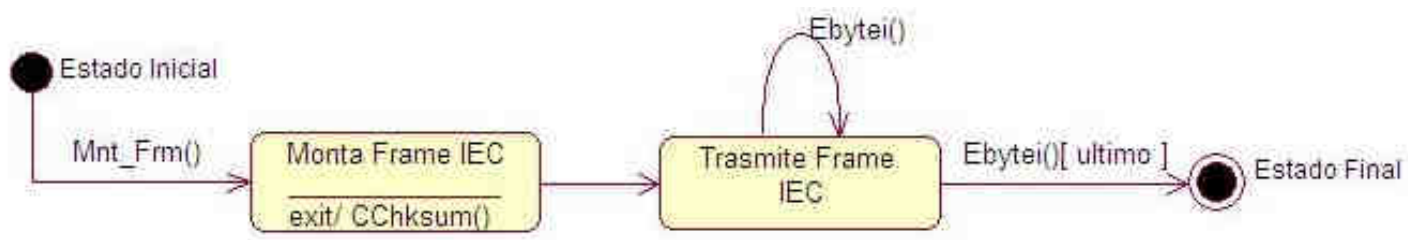

Figura 34 - Diagrama de estados da classe E_FRM_IEC 


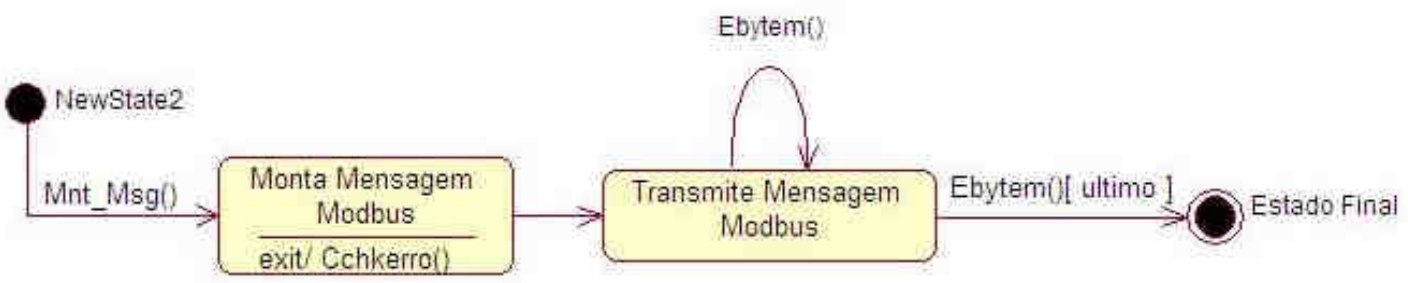

Figura 35 - Diagrama de estados da classe E_MSG_MOD

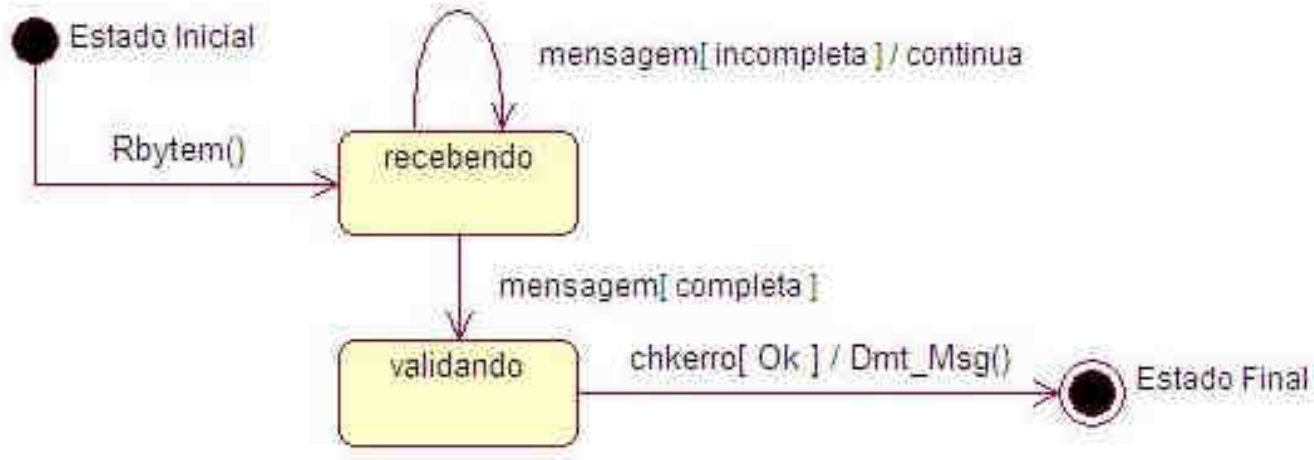

Figura 36 - Diagrama de estados da classe R_MSG_MOD

Ainda para o caso de uso 1 temos a participação da classe CV_INIC responsável pela conversão de formato IEC para Modbus na inicialização e sendo o seu diagrama de estados mostrado na Figura 37.

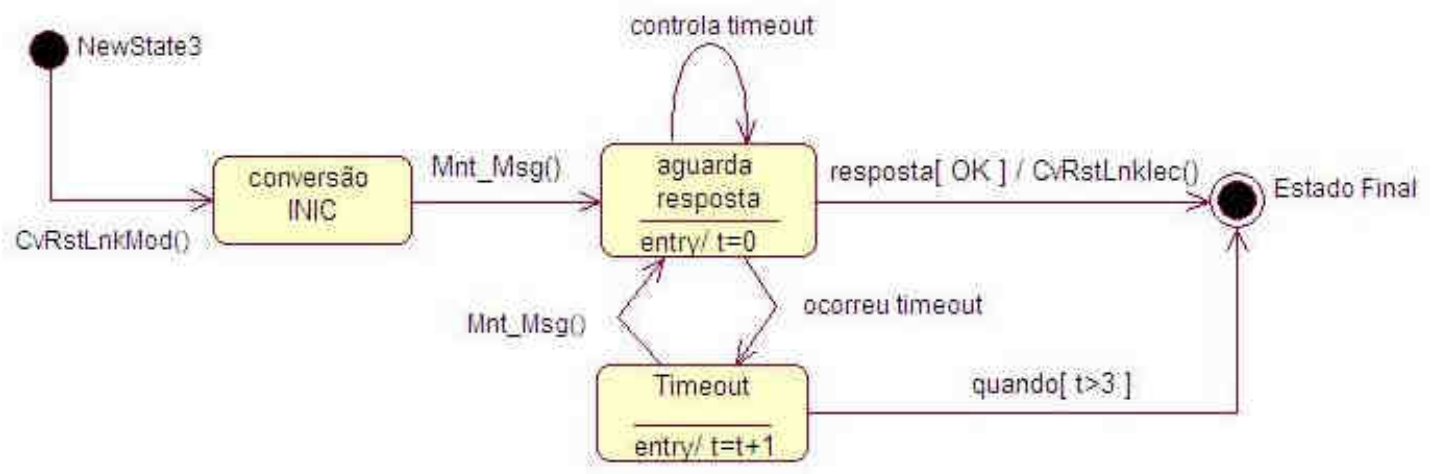

Figura 37 - Diagrama de estados da classe CV_INIC

Para o caso de uso 4 temos a participação da classe CV_TC responsável pela conversão de formato IEC para Modbus na execução de um telecomando e sendo o seu diagrama de estados mostrado na Figura 38. 


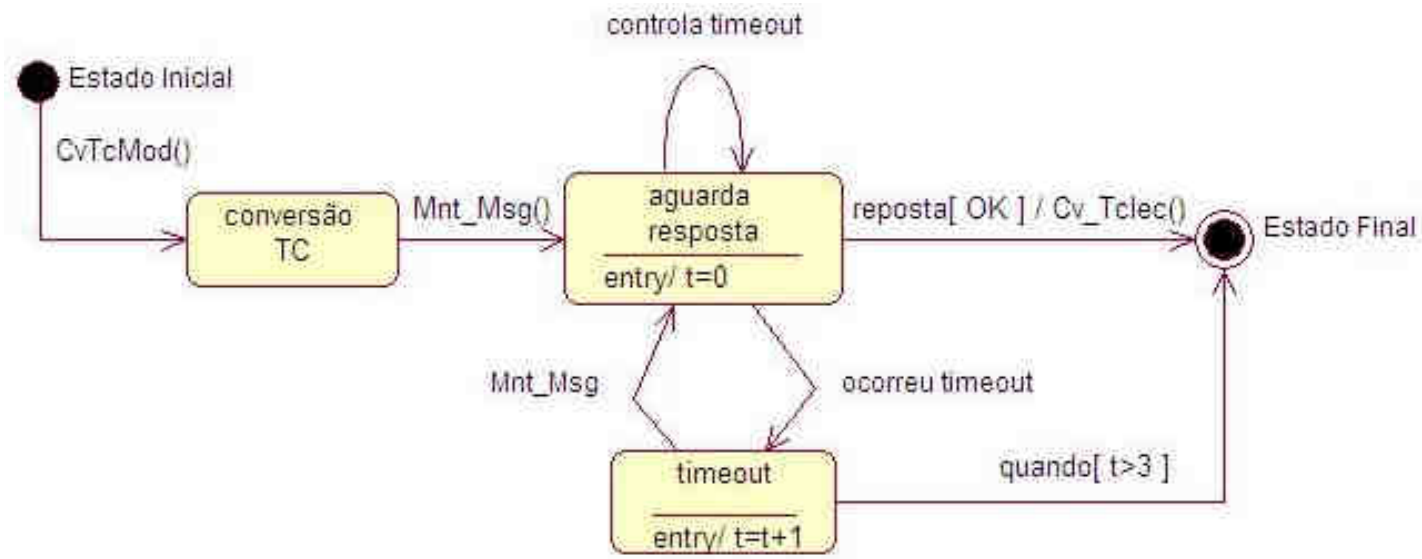

Figura 38 - Diagrama de estados da classe CV_TC

A classe T_FRM_IEC tem participação em todos os casos de uso. Para uma melhor visualização dos estados envolvidos em cada um deles, os seus diagramas de estado serão mostrados considerando apenas os estados envolvidos em cada um dos casos de uso. Portanto as Figuras 39, 40 e 41 mostram os estados desta classe envolvidos na inicialização, na função de seleção de um ponto a ser comandado e na função de execução do comando no ponto selecionado.

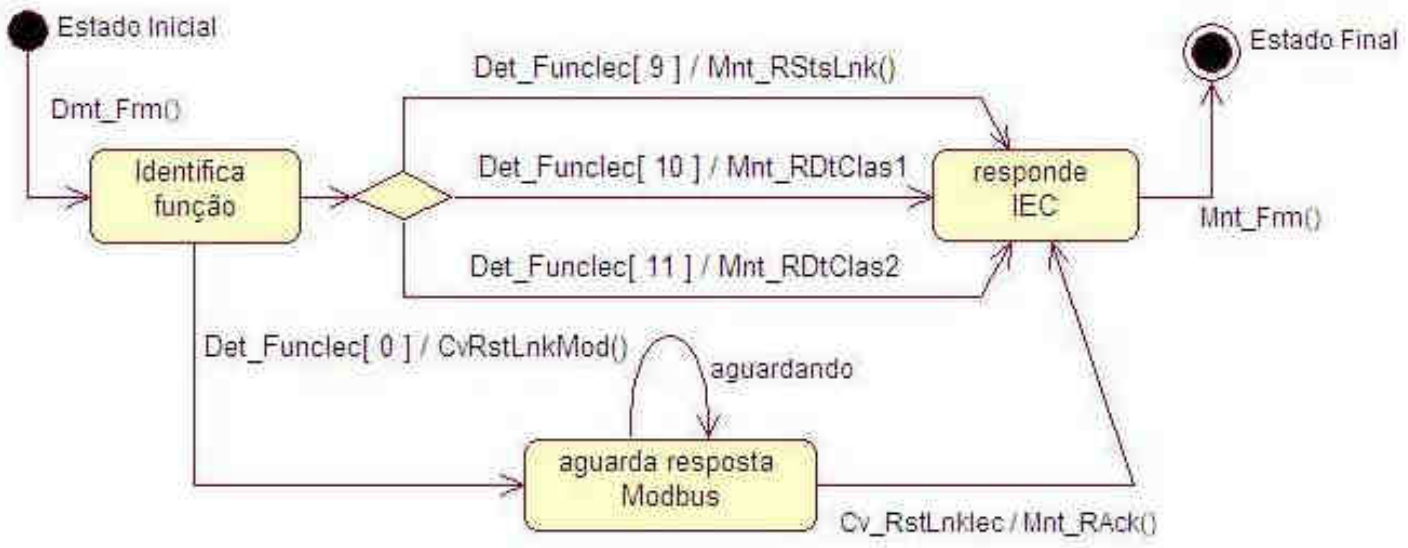

Figura 39 - Diagrama de estados da classe T_FRM_IEC na inicialização 


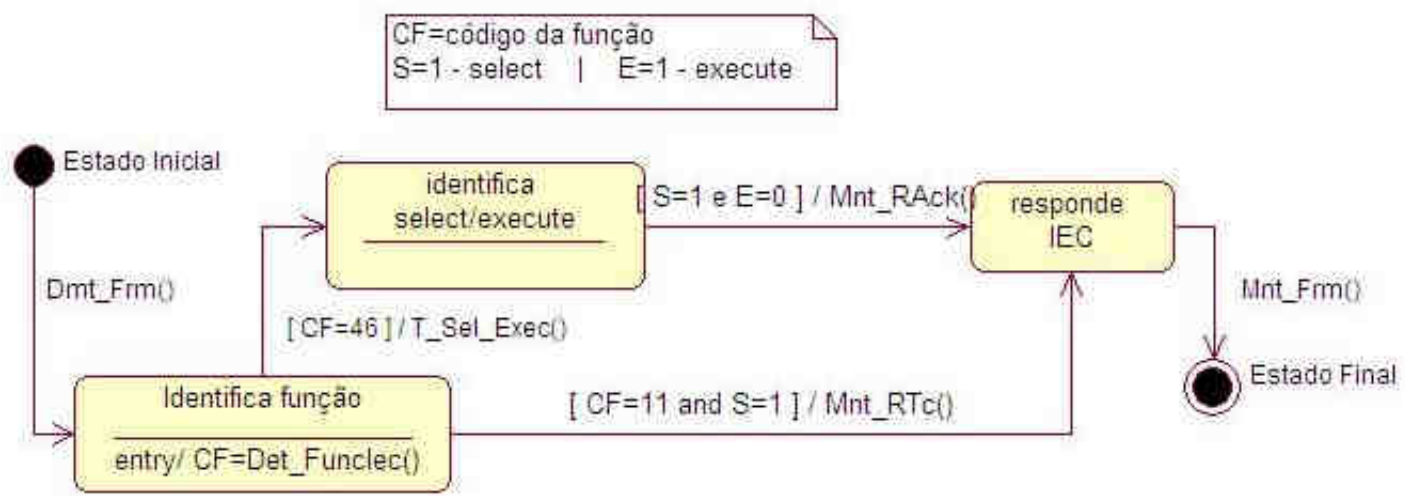

Figura 40 - Diagrama de estados da classe T_FRM_IEC na seleção de ponto $\mathrm{CF}=$ código da funçầo $S=1$ - select I $E=1$ - execute

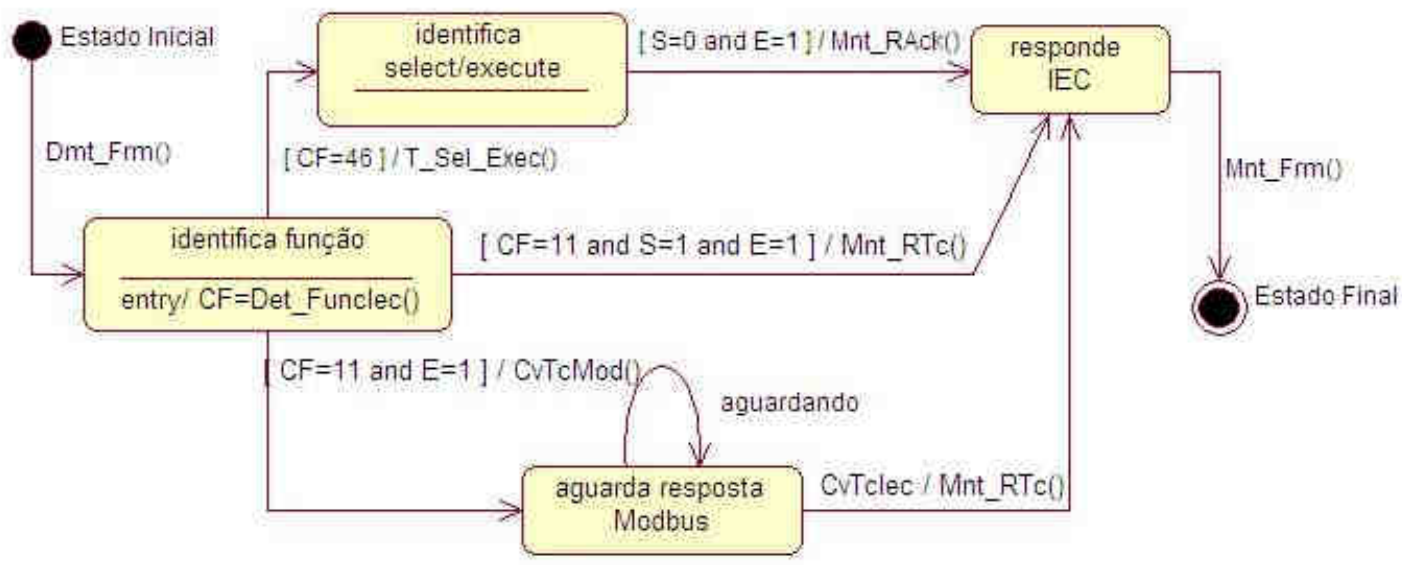

Figura 41 - Diagrama de estados da classe T_FRM_IEC na execução de comando

Na fase de análise utilizando a UML procuramos definir de forma clara as necessidades do sistema a ser implementado. Na fase de projeto podem surgir; por características da linguagem de programação utilizada; novas classes necessárias à implementação do software. 


\section{5 -TESTES}

Com o objetivo de avaliar as vantagens e desvantagens do desenvolvimento de funções de um conversor de protocolos para a área de automação elétrica baseado na utilização da UML e do paradigma de programação orientada a objetos, foi utilizada uma configuração de computadores PC interligados conforme indicado na Figura 45.

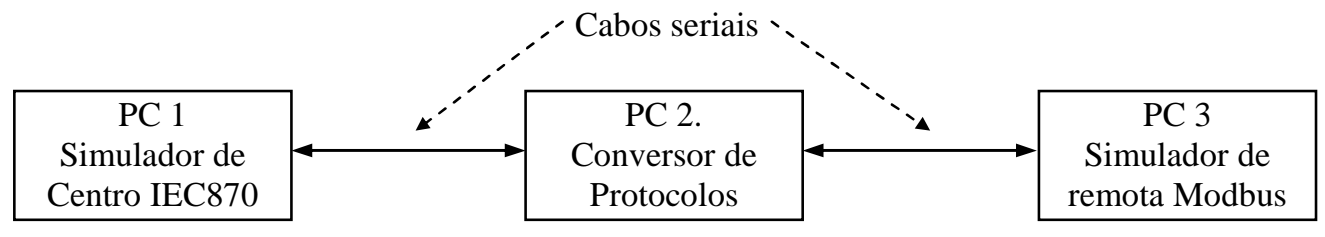

Figura 42 - Configuração de Hardware para testes da implementação.

No microcomputador 1 foi instalado o sistema operacional Windows XP e rodando sob ele o software de supervisão e controle ActionView. Este software foi configurado para implementar a comunicação com uma UAC utilizando o protocolo IEC 60870-101 e endereçando a UAC de endereço 1. A comunicação era realizada através da porta COM1 que estava configurada para trabalhar com 8 bits de dados, paridade par, 1 stop bit e velocidade de 9600 bps.

No microcomputador 3 foi instalado o sistema operacional Windows 98 e rodando sob ele, em uma janela DOS, o programa mbsim. O programa mbsim simula um slave do protocolo MODBUS localizado no endereço 01. A comunicação era realizada em modo RTU através da porta COM1 que estava configurada para trabalhar com 8 bits de dados, paridade par, 1 stop bit e velocidade de 9600 bps.

No microcomputador 2 foi instalado o sistema operacional Windows 98 e rodando sob ele, em uma janela DOS, o programa do conversor de protocolos, desenvolvido na linguagem Turbo $\mathrm{C}++$. Para se obter características semelhantes a um sistema multitarefa, todas as funções referentes à comunicação através das portas seriais, foram implementas por meio de interrupção. As duas portas de comunicação serial COM1 e COM2 estavam configuradas para trabalhar com 8 bits de dados, paridade par, 1 stop bit e velocidade de 9600 bps. 
No capítulo 4, com o objetivo de realizar o estudo proposto, foram especificadas dentre todas as funções previstas na funcionalidade dos protocolos IEC 60870 e Modbus, as funções de inicialização, leitura de valores digitais, leitura de valores analógicos, e escrita de valor digital (telecomando).

Para geração do código utilizado pelo conversor de protocolos nos testes de comunicação entre Sistema SCADA/Conversor/UAC, foram utilizadas apenas duas das funções estudadas: inicialização e escrita de valor digital (telecomando). Esta escolha deve-se ao fato destas duas funções necessitarem de um maior número de troca de mensagens entre Sistema SCADA/Conversor/UAC.

Para a implementação destas duas funções, foi necessário implementar no conversor de protocolos funções para responder as solicitações cíclicas de dados classe 1 e 2 que são realizadas pelo Sistema SCADA após a inicialização. Se estas funções não fossem implementadas, o Sistema SCADA entenderia que o link de comunicação com a UAC estava inativo, iniciando assim uma nova sequência de inicialização..

As dificuldades iniciais encontradas foram com relação ao tipo de frame utilizado pelo ActionView, já que a especificação da norma IEC 60870-5-101 permite a utilização de frames de tamanho fixo e variável, sendo a escolha do tipo utilizado particular para cada sistema.

Após a implementação correta do tipo de frame utilizado foi possível realizar uma sequência completa de inicialização, solicitação cíclica de dados classe 1 e 2 e telecomando, retornando a solicitação cíclica de dados classe 1 e 2 .

Nas Tabelas III, V e VI são apresentadas as mensagens que foram trocadas entre o ActionView o conversor de protocolos e o simulador Modbus. Elas foram montadas em uma estrutura de grade com a especificação de cada campo dos frames IEC e mensagens Modbus, permitindo assim a visualização da composição de cada uma das funções realizadas. A Tabela III mostra s sequência de mensagens para a inicialização. A Tabela IV descreve a sequência de mensagens para seleção de um ponto a ser comandado e a Tabela VI a sequência para execução do comando. A Tabela $\mathrm{V}$ descreve cada um dos campos existentes nas mensagens e frames. 
Tabela III - Sequência de Mensagens pata Inicialização

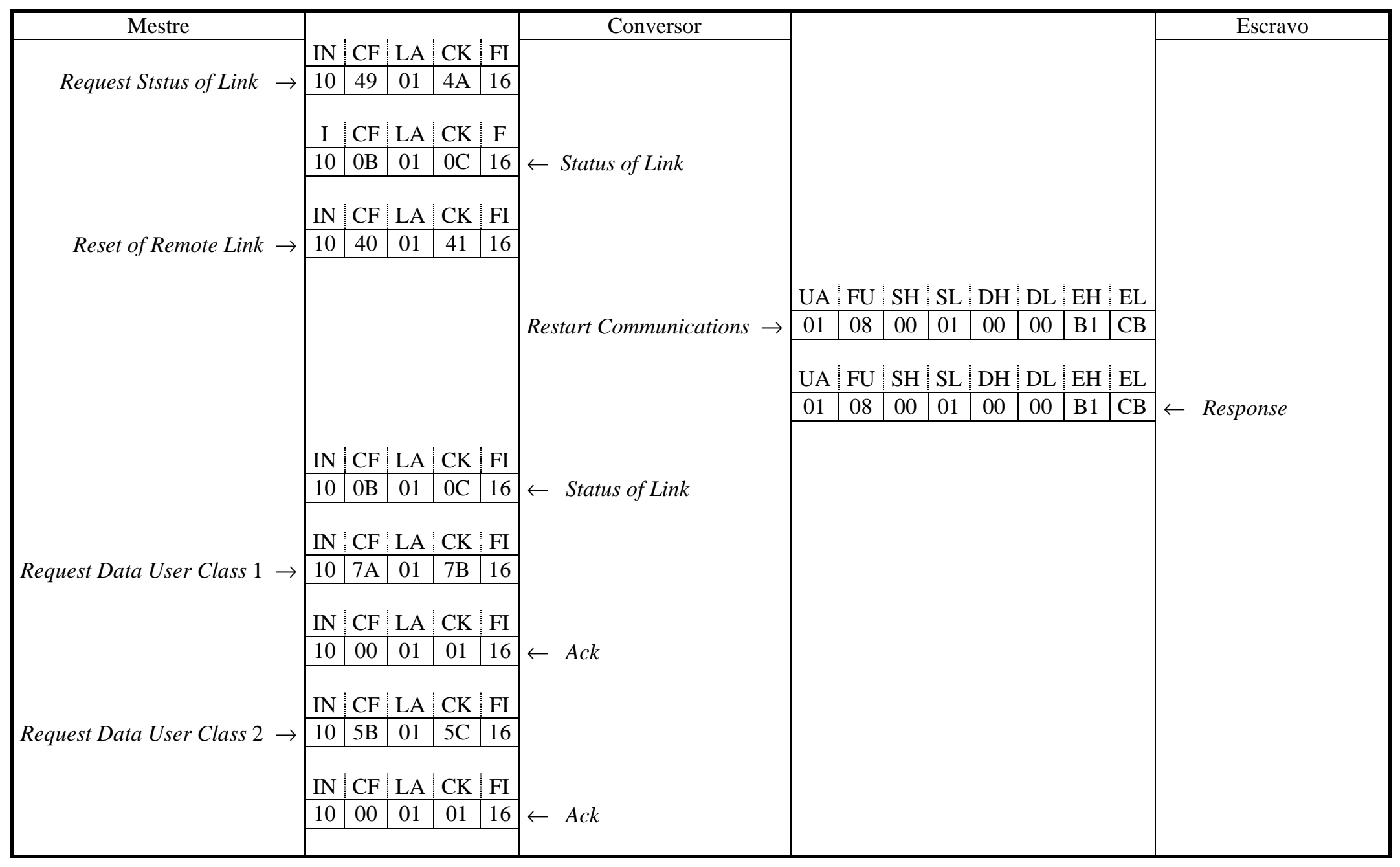


Tabela IV - Sequência de Mensagens para Select

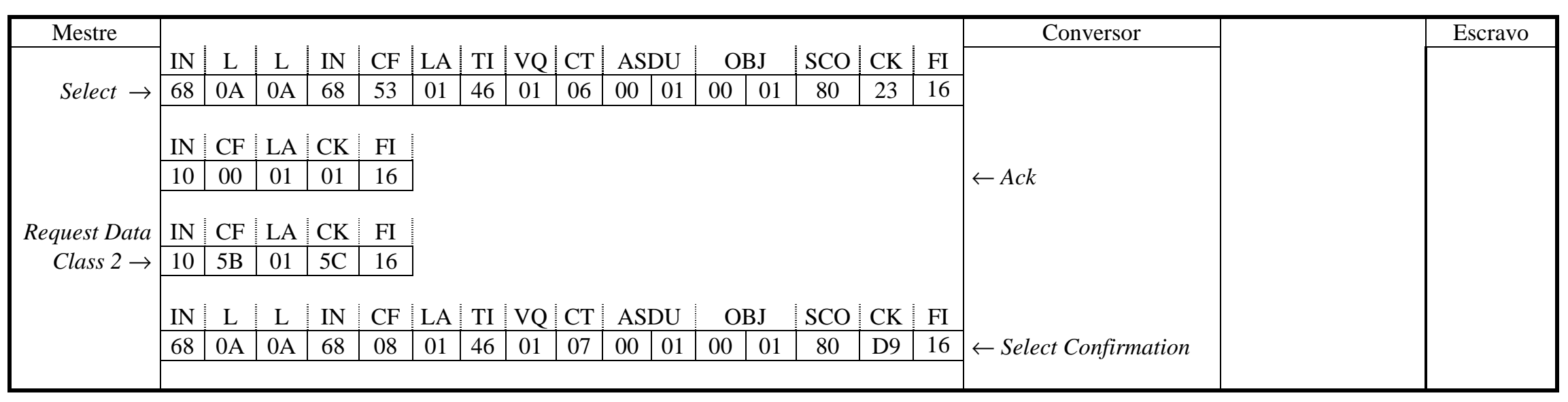

Tabela V - Legenda dos Campos das Mensagens IEC e Modbus

\begin{tabular}{|c|l|c|c|l|}
\hline \multicolumn{3}{|c|}{ Identificação dos Campos das Mensagens } \\
\hline \multicolumn{3}{|c|}{ IEC 60870-5-101 } & \multicolumn{2}{|c|}{ Modbus } \\
\hline IN & Caractere de início & UA & Endereço da UAC \\
\hline L & Comprimento do frame & FU & Código da função \\
\hline CF & Control Field & SH & Subfunction Hi \\
\hline LA & Link Address & SL & Subfunction Lo \\
\hline TI & Type Identification & DH & Data Hi \\
\hline VQ & Variable Structure Qualifier & DL & Data Lo \\
\hline CT & Cause of Transmission & EH & Error Check Hi \\
\hline ASDU & Application Service Data Unit & & EL & Error Check Lo \\
\hline OBJ & Information Object Address & CH & Coil Address Hi \\
\hline SCO & Qualificação do comando & CL & Coil Address Lo \\
\hline CK & Cheksum & FH & Force Data Hi \\
\hline FI & Caractere de fim & FL & Force Data Lo \\
& & & \\
\hline
\end{tabular}


Tabela VI - Sequência de mensagens para Execute

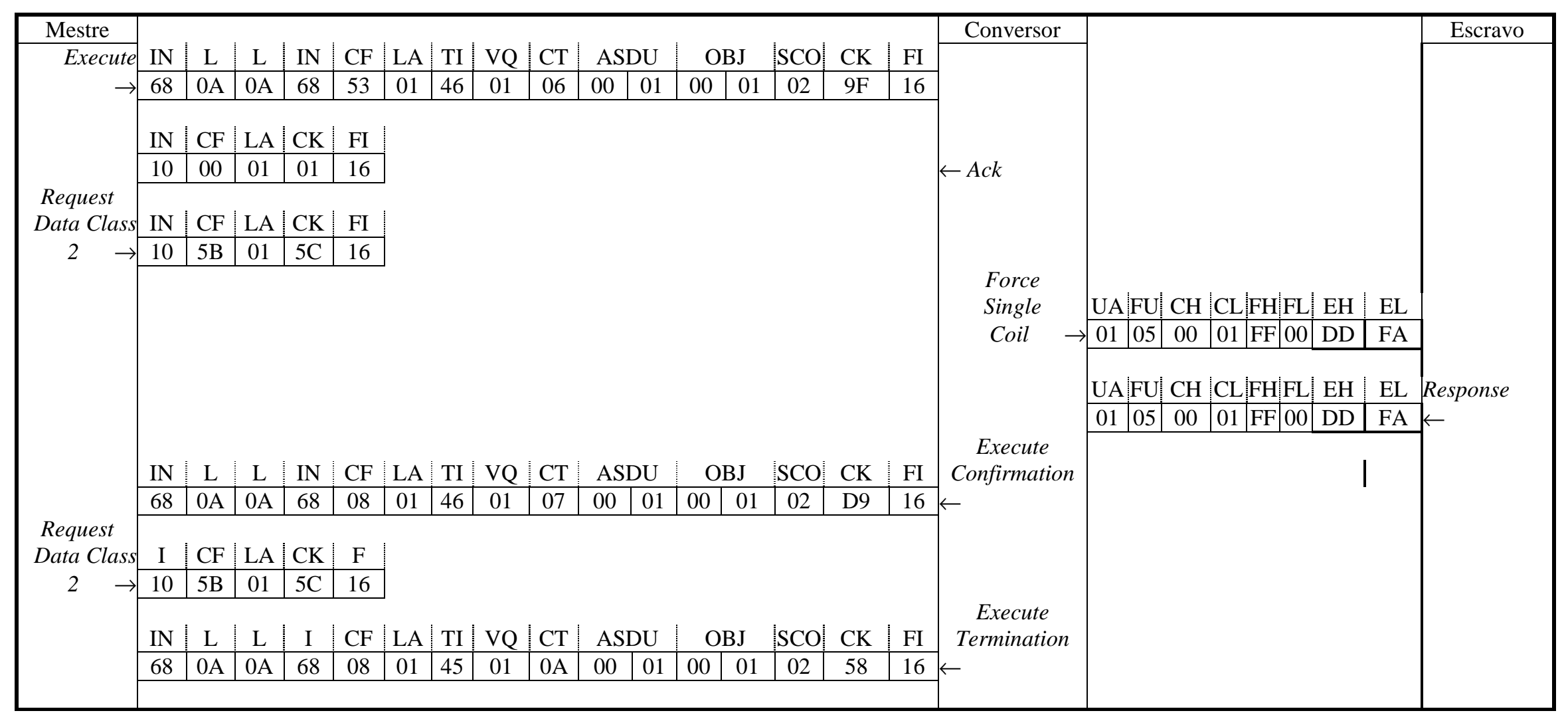




\section{6 - CONCLUSÃO}

A utilização da UML como ferramenta para a análise, projeto e desenvolvimento, mostrou-se eficiente para o aumento gradativo do conhecimento sobre o sistema objeto deste estudo. Por outro lado nota-se um aumento substancial no tempo de desenvolvimento, isso graças as grande quantidade de documentos que acabam sendo gerados para uma adequada representação do sistema. Com a utilização de uma ferramenta de software, o Rational Rose, para a criação e manutenção dos diagramas UML, adicionamos características de segurança e integridade aos nomes de classes, atributos e operações, evitando assim duplicidade de definições e facilidade de uso quando da criação dos demais diagramas de especificação do sistema.

Alterações que foram surgindo com o desenvolvimento do sistema e que necessitavam serem implementadas nos diagramas criados foram realizadas de forma bastante simples e rápida, com a propagação automática destas alterações para os demais diagramas. A padronização semântica e sintática da UML reduz o tempo para se conhecer e entender o funcionamento de um sistema especificado.

A principal vantagem a ser considerada é quando da implementação de um novo conversor de protocolos, com a troca de um dos protocolos especificados. Temos uma redução no tempo de desenvolvimento, pois serão redefinidas parte das classes já especificadas e uma parcela do software.

Este trabalho limitou-se a implementar apenas duas funções existentes no protocolo IEC 60870-5-101, realizando a comunicação de um sistema Scada com apenas uma UAC. Para futuro pode-se procurar implementar um número maior de funções e realizar a comunicação com mais de uma UAC, sendo necessária a utilização de uma linguagem de programação orientada a objetos, que possa ser executada em um ambiente multitarefa real e ainda com possibilidade de utilização de threads..

Com relação às classes criadas, elas podem ser implementadas a partir de uma superclasse que contenha os atributos dos frames dos protocolos envolvidos, mas que sejam derivadas por herança em classes mais especializadas, responsáveis pelo tratamento individual de cada função utilizada pelo conversor de protocolos. 


\section{7 - REFERÊNCIAS BIBLIOGRÁFICAS}

[1] JARDINI, J.A.; Automação de usinas, subestações e distribuições de energia. Edição acadêmica, São Paulo, 1996.

[2] MOTOROLA, Modbus Protocol Reference Guide, MODICON, North Andover, 1993.

[3] IEC 60870-5-3, Telecontrol Equipment Systems - Part 5: Transmission Protocols - Section 3: General Structure of application data, IEC, 1992.

[4] IEC 60870-5-1, Telecontrol Equipment Systems - Part 5: Transmission Protocols - Section 1: Transmission frame formats, IEC, 1990.

[5] IEC 60870-5-101, Telecontrol Equipment Systems - Part 5: Transmission Protocols - Section 101: Companion standard for basic telecontrol tasks, IEC, 1995.

[6] IEC 60870-5-4, Telecontrol Equipment Systems - Part 5: Transmission Protocols - Section 4: Definition and coding of application information elements IEC, 1993.

[7] IEC 60870-5-5, Telecontrol Equipment Systems - Part 5: Transmission Protocols - Section 5: Basic Application functions IEC, 1995.

[8] GILLEANES T.A.G., UML - Uma Abordagem Prática. Novatec, São Paulo, 2004.

[9] BEZERRA, E., Princípios de Análise e Projeto de Sistemas com UML. CAMPUS, Rio de Janeiro, 2003.

[10] BOOCH, G., RUMBAUGH, J. e JACOBSON, I., UML - Guia do Usuário. CAMPUS, Rio de Janeiro, 2000.

[11] OMG, Object Management Group, Resource Page, 2005. Disponível em www.omg.org. Acesso em: 2 jun. 2005.

[12] IEC 60870-5-2, Telecontrol Equipment Systems - Part 5: Transmission Protocols - Section 2: Link Transmission Procedures, IEC, 1992.

[12] IEC 60870-1-1, Telecontrol Equipment Systems - Part 1: General Considerations - Section 1: General Principles, IEC, 1984. 
ANEXO 1 - Dicionário de Dados

\begin{tabular}{|c|c|c|c|c|}
\hline Nome & Tipo & Formato & Caso de Uso & Descrição \\
\hline CV_INIC & Classe & --- & 1 & $\begin{array}{l}\text { Realiza a conversão de solicitação de inicialização do formato IEC 60870-5-101 para } \\
\text { o formato Modbus }\end{array}$ \\
\hline CV_LA & Classe & $\begin{array}{l}-- \\
\end{array}$ & 3 & $\begin{array}{l}\text { Realiza a conversão de solicitação de leitura de dados analógicos do formato IEC } \\
60870-5-101 \text { para o formato Modbus }\end{array}$ \\
\hline CV_LD & Classe & --- & 2 & $\begin{array}{l}\text { Realiza a conversão de solicitação de leitura de dados digitais do formato IEC } \\
60870-5-101 \text { para o formato Modbus }\end{array}$ \\
\hline $\mathrm{CV}_{-} \mathrm{TC}$ & Classe & --- & 4 & $\begin{array}{l}\text { Realiza a conversão de solicitação de telecomando select before operate do formato } \\
\text { IEC 60870-5-101 para o formato Modbus (force single coil) }\end{array}$ \\
\hline E_FRM_IEC & Classe & --- & $1,2,3,4$ & $\begin{array}{l}\text { Realiza a montagem, o cálculo do Cheksum e envio de frames IEC 60870-5-101 para } \\
\text { o sistema Scada }\end{array}$ \\
\hline E_MSG_MOD & Classe & --- & $1,2,3,4$ & $\begin{array}{l}\text { Realiza a montagem, o cálculo do Chekerro e envio de mensagens Modbus para a } \\
\text { UAC }\end{array}$ \\
\hline R_FRM_IEC & Classe & --- & $1,2,3,4$ & $\begin{array}{l}\text { Realiza a recepção de frames IEC 60870-5-101 provenientes do sistema Scada e a } \\
\text { verificação do seu Chksum. }\end{array}$ \\
\hline R_MSG_MOD & Classe & --- & $1,2,3,4$ & $\begin{array}{l}\text { Realiza a recepção de mensagens modbus provenientes da UAC e a verificação do } \\
\text { seu Chkerro. }\end{array}$ \\
\hline Asdu & Atributo & Carray[] & $1,2,3,4$ & Estrutura de campos de uma ASDU (formato IEC 60870-5-101) \\
\hline Campo CF & Atributo & Byte & $1,2,3,4$ & $\begin{array}{l}\text { Informações sobre o sentido da mensagem, tipo de serviço e controle de perda ou } \\
\text { duplicação de mensagens de frames IEC 60870-5-101 trocados entre o sistema Scada } \\
\text { e o conversor de protocolos. }\end{array}$ \\
\hline Comando & Atributo & Unsigned int & 4 & Estado do telecomando select before operate IEC 60870-5-101(On/Off). \\
\hline Dados & Atributo & Unsigned int & 1 & Valores para indicar limpeza ou não do log de eventos na UAC. \\
\hline EndIni & Atributo & Unsigned int & 2,3 & Endereço inicial dos pontos a serem lidos na UAC. \\
\hline EndLnk & Atributo & Byte & $1,2,3,4$ & Endereço IEC 60870-5-101da UAC. \\
\hline EndPonto & Atributo & Unsigned int & 4 & Endereço do ponto a ser telecomandado \\
\hline Endutr & Atributo & Byte & $1,2,3,4$ & Endereço Modbus da UAC. \\
\hline Função & Atributo & Byte & $1,2,3,4$ & Código da função Modbus \\
\hline
\end{tabular}




\begin{tabular}{|c|c|c|c|c|}
\hline Informação & Atributo & CArray[QtdInf] & 2,3 & Informação solicitada \\
\hline Lpdu & Atributo & Carray[] & $1,2,3,4$ & Estrutura do frame IEC 60870-5-101 \\
\hline Msg & Atributo & Carray[] & $1,2,3,4$ & Estrutura da mensagem Modbus \\
\hline NumPts & Atributo & Unsigned int & 2,3 & Quantidades de pontos a serem lidos na UAC (formato Modbus) \\
\hline QtdInf & Atributo & Byte & 2,3 & Quantidade de bytes com informação provenientes da UAC (formato Modbus) \\
\hline Subfunção & Atributo & Unsigned int & 1 & Código da Sub_função de diagnóstico para resetar porta de comunicação na UAC. \\
\hline Cchkerro & Método & --- & $1,2,3,4$ & Calcula o Chkerro de mensagem Modbus recebida/a enviar da/para a UAC \\
\hline CChksum & Método & --- & $1,2,3,4$ & $\begin{array}{l}\text { Calcula o Chksum do frame IEC 60870-5-101 recebido/a enviar do/para sistema } \\
\text { Scada }\end{array}$ \\
\hline Cv_RLaIec & Método & --- & 3 & $\begin{array}{l}\text { Converte dados analógicos do formato Modbus provenientes da UAC para o formato } \\
\text { IEC 60870-5-101 destinados ao sistema Scada }\end{array}$ \\
\hline Cv_RLdIec & Método & --- & 2 & $\begin{array}{l}\text { Converte dados digitais do formato Modbus provenientes da UAC para do formato } \\
\text { IEC 60870-5-101 destinados ao sistema Scada }\end{array}$ \\
\hline Cv_RstLnkIec & Método & --- & 1 & $\begin{array}{l}\text { Converte reset da porta de comunicação da UAC (função modbus) proveniente da } \\
\text { UAC em reset de link IEC 60870-5-101 destinado ao sistema Scada }\end{array}$ \\
\hline Cv_TcIec & Método & --- & 4 & $\begin{array}{l}\text { Converte resposta a telecomando force single coil Modbus proveniente da UAC para } \\
\text { telecomando select before operate IEC 60870-5-101 destinado ao sistema Scada }\end{array}$ \\
\hline CvLaMod & Método & --- & 3 & $\begin{array}{l}\text { Converte solicitação de leitura de dados analógicos do formato IEC 60870-5-101 pa- } \\
\text { ra o formato Modbus (função read holding registers) }\end{array}$ \\
\hline CvLdMod & Método & --- & 2 & $\begin{array}{l}\text { Converte solicitação de leitura de dados digitais do formato IEC 60870-5-101 para o } \\
\text { formato Modbus (função read input status) }\end{array}$ \\
\hline CvRstLnkMod & Método & --- & 1 & $\begin{array}{l}\text { Converte reset de link IEC 60870-5-101 em reset de porta de comunicação da UAC } \\
\text { (função Modbus) }\end{array}$ \\
\hline CvTcMod & Método & --- & 4 & $\begin{array}{l}\text { Converte solicitação de telecomando select before operate do formato IEC 60870-5- } \\
101 \text { para o formato Modbus (função force single coil) }\end{array}$ \\
\hline Det_Funclec & Método & --- & $1,2,3,4$ & Determina qual a função IEC 60870-5-101 solicitada para o conversor \\
\hline Dmt_Frm & Método & --- & $1,2,3,4$ & Desmonta frame IEC 60870-5-101 proveniente do sistema Scada \\
\hline Dmt_Msg & Método & --- & $1,2,3,4$ & Desmonta mensagem Modbus proveniente da UAC \\
\hline Ebytei & Método & --- & $1,2,3,4$ & Envia byte a byte um frame IEC $60870-5-101$ \\
\hline Ebytem & Método & --- & $1,2,3,4$ & Envia byte a byte uma mensagem Modbus para a UAC \\
\hline Mnt_Frm & Método & --- & $1,2,3,4$ & Monta frame IEC 60870-5-101 a enviar para o sistema Scada \\
\hline
\end{tabular}




\begin{tabular}{|l|l|l|c|l|}
\hline Mnt_Msg & Método & --- & $1,2,3,4$ & Monta mensagem Modbus a enviar para a UAC \\
\hline Mnt_RAck & Método & --- & 1,4 & Monta frame com confirmação a enviar para o sistema Scada \\
\hline Mnt_RDtClas1 & Método & --- & 1 & Monta frame com dados de Classe 1 IEC 60870-5-101 a enviar para o sistema Scada \\
\hline Mnt_RdtClas2 & Método & --- & $1,2,3$ & Monta frame com dados Classe 2 IEC 60870-5-101 a enviar para o sistema Scada \\
\hline Mnt_RNack & Método & --- & 1,4 & $\begin{array}{l}\text { Monta frame com informação de dados não disponíveis a enviar para o sistema } \\
\text { Scada }\end{array}$ \\
\hline Mnt_RStsLnk & Método & --- & 1 & Monta frame com resposta de status do link a enviar para o sistema Scada \\
\hline Mnt_RTc & Método & --- & 4 & Monta frame com resposta a telecomando a enviar para o sistema Scada \\
\hline NACK & Método & --- & $1,2,3,4$ & Monta resposta de mensagem não aceita a enviar para o sistema Scada \\
\hline Rbytei & Método & --- & $1,2,3,4$ & Trata recepção byte a byte de frame IEC 60870-5-101 proveniente do sistema Scada \\
\hline Rbytem & Método & --- & $1,2,3,4$ & Trata recepção byte a byte de mensagem Modbus \\
\hline T_Sel_Exec & Método & --- & 4 & Trata sequencia de select/execute IEC 60870-5-101 \\
\hline T_Timeout & Método & --- & $1,2,3,4$ & Trata timeout de recepção Modbus \\
\hline
\end{tabular}

